\title{
Spillovers, integration and causality in LME non-ferrous metal markets
}

\author{
${\text { Cetin } \text { Ciner }^{\mathrm{a}}, \text { Brian Lucey }}^{\mathrm{b}, *}$, Larisa Yarovaya $^{1}$ \\ ${ }^{a}$ Cameron Business School, UNC Wilmington, 601 S. College Road, Wilmington NC 28403 USA \\ ${ }^{b}$ Trinity Business School, Trinity College Dublin, Dublin 2, Ireland 8 University of Sydney Business School, Sydney, \\ Australia \\ ${ }^{c}$ Lord Ashcroft International Business School, Anglia Ruskin University, Chelmsford CM1 1SQ, United Kingdom
}

\begin{abstract}
We examine the interrelationships in the global base metal markets over a 22 year period 1994-2016 using a variety of econometric methods. The results demonstrate the high intensity of both return and volatility spillovers across the selected markets. Furthermore, the degree of co-movements varies among time and frequencies. The study also contributes to the contagion literature since the results revealed the increase in co-movements after the financial crisis. Aluminium is found to be the driving force, with significant influence across all methodologies. The findings show that the behavior of the non-ferrous metals is similar to other conventional asset classes, like equities and bonds, justifying the position that metals have become an investment class.
\end{abstract}

Keywords: Integration, base metals, information transmissions, Generalized VAR model, lead, Zinc, aluminum, Tin

JEL Codes : C32, F18, F49, Q37

\section{Introduction}

Despite the importance of industrial metals, both from an industrial and a financial perspective, relatively little has been written regarding their behaviour as a (possible) asset class. As with other commodities, non-ferrous metals may be of interest to investors for asset allocation and diversification benefits. However, the question whether commodities as a whole are an asset class is still under debate. We hypothesise that in order to be considered as a separate asset class non-ferrous metals should demonstrate a high level of integration, and also respond to the common shocks in a similar manner. To this extent, the return and volatility transmission across those markets should demonstrate similar patterns (see Erb and Harvey (2006); Gorton and Rouwenhorst (2006)). For the most part the unspoken assumption is that base or non-ferrous metals can be seen as an asset class. The purpose of this note is to examine, from one set of perspectives, that of spillovers, whether this is in fact warranted.

Within existing research on non-ferrous metals research the bulk of the analysis has focused on futures markets. Marshall et al. (2013) examined liquidity commonality in commodity futures markets using data from energy, industrial and precious metals, as well as livestock commodities, and found no evidence of a consitent link between stock and commodity liquidity. Demirer et al. (2015) analysed the herd behaviour in commodities futures markets, including energy, livestock, grains and metals, found no significant effect of the stock market on herd behaviour in the commodity futures market rejecting the commodity financialization hypothesis. Fernandez (2010) has examined long memory

\footnotetext{
${ }^{*}$ Corresponding Author

Email addresses: Email:cinerc@uncw.edu (Cetin Ciner), Email: blucey@tcd.ie (Brian Lucey), Email:drlarisayarovaya@gmail.com (Larisa Yarovaya)
} 
and Belousova and Dorfleitner (2012) has shown their usefulness in portfolio formation. In addition research has been also been conducted on non-ferrous metals.

Chinn and Coibion (2014) analysed whether futures prices are accurate and unbiased predictors of subsequent prices, and demonstrated that base metals are poor predictors. Dooley and Lenihan (2005) employed forecasting experiments to predict future lead and zinc prices highlighting the difficulties of the price forecasting. Gil-Alana and Tripathy (2014) analysed volatility persistence and asymmetry in non-ferrous metals markets in India. The results show a high degree of volatility persistence and evidence of asymmetry in the majority of series. Cummins et al. (2015) analysed behavioural influences on on-ferrous metal markets. The findings suggest that non-ferrous metals markets are not immune to trader biases influencing the setting of prices. For example, lead, zinc and aluminium alloy demonstrated anomalous price reaction around psychologically important price points, particularly following a breach of $\$ 1000$ point (Cummins et al. (2015)). Analysis of realised volatility spillovers in non-ferrous metals markets by Todorova et al. (2014) reports significant interrelationship between markets. ${ }^{1}$

Fernandez (2016) examined spot-futures prices relationships in six base metals traded on the London Metal Exchange (LME). Stronger linkages between futures and spot returns are found during the periods of high shocks. Furthermore, Fernandez (2016) demonstrated the associations between interest-adjusted basis and the business cycles of consumption/production of the aluminium, copper, lead, nickel, tin and zinc, as well as the business cycle of industrial production of various countries (e.g. US, G7, OECD, Russia and China). Omura et al. (2018) provided evidence of linkages between the convenience yield and the realised volatility using the intraday LME spot and futures prices of non-ferrous metals.

Nonetheless, the extent of research on the financial, as opposed to the economic, aspects of nonferrous metals, is relatively small. Moreover, as noted in Todorova et al. (2014) this is surprising, given the reasonable amount of knowledge we have regarding how returns and levels of non industrial metal prices spillovers and interrelationships. Nonetheless the issue of return and volatility transmission is under explored in the literature and requires further attention.

This paper contributes to existing knowledge in several ways. First, we present novel empirical evidence on return and volatility transmission across seven non-ferrous markets offered on the London Metal Exchange. The London Metal Exchange, LME, is the leading global centre for non-precious metal trading and thus represents a useful starting point to examine non-ferrous metal interactions. Using the Diebold and Yilmaz (2012) methodology we show the dynamics and intensity of spillover over a 22 years period, i.e. from 12 January 1994 -19 October 2016, providing a conclusion as to which markets are net-recipients and net-contributors of spillovers. Second, this paper employs two volatility measures, Squared Volatility and Parkinson range volatility, contributing better to the debate around which volatility estimators are the most appropriate to use in spillovers studies. Third, we further augment the existing literature by providing the analysis of co-movement between selected markets using the wavelet coherence framework. The wavelet power spectrum provides a useful information on

\footnotetext{
${ }^{1}$ Another literature strand has focused on precious metals futures (see as examples Batten et al. (2010); Sensoy (2013); Bosch and Pradkhan (2015), to name but a few. See O'Connor et al. (2015) for a comprehensive review of research on gold)
} 
synchronisation between each pairs of metals in different time-frequency domains, while the results of wavelet multi-scale phase analysis allows to understand the positive/negative nature of these relationships. Finally, We also use the Hatemi-J (2012) approach to surface asymmetric causality amongst these metals.

Our findings are helpful for portfolio managers who are interested in analysis of the behaviour on metals markets to design optimal investment portfolio and to diversify risks. The analyses of commodities in general, and particularly the analysis that is presented in our paper, can also perhaps help financial analysts to provide comprehensive recommendations on investment opportunities available for investors apart from more traditional assets like stock, bonds, and derivatives markets. These findings can be also interesting for managers of exchanged-traded commodities and exchange-traded funds. To the extent that these markets move together or not, they can be seen as an asset class. Identification of the interrelationships between the components allows greater flexibility in investment or investment product design.

The remainder of the paper is organized as follows. Section 2 reviews literature on the metal market integration, Section 3 describes the dataset and the methodology used in our empirical analysis, while Section 4 reports and discusses the empirical results. Finally, Section 5 concludes the paper.

\section{Previous research on integration of the global metal markets}

The economic importance of metals to the world economy cannot be overstated. A solid analysis of the economic impact is Arezki et al. (2015). LME offers opportunities to invest in a number of non-ferrous metals, such as aluminium, aluminium alloy, copper, lead, tin and zinc. All these metals have a high industrial importance, and therefore the volatility on these metal markets has attracted attention within the industry. Besides, the increased interest in non-ferrous markets has recently been shown by investors and speculators. Thus, as major financial commodities, industrial metals have attracted research on their pricing. Examples include papers such as Liu et al. (2014), Beckmann and Czudaj (2013), and Geman and Scheiber (2014).

A number of researchers have noted the importance of industrial metals for the general financial sector. Jacobsen et al. (2016) suggests that industrial metals can act as important signals of general financial conditions, especially for equity market returns. Looking at commodity hedging and their safe haven status. This is congruent with findings in Delatte and Lopez (2013). Agyei-Ampomah et al. (2014) finds safe haven properties in industrial metals, in particular copper, against sovereign bond adverse events. Although metals markets are often considered as a safe haven during periods of financial turmoil, and non-ferrous metals similarly often viewed as a hedging products, the increased activity in metals consequently increased the volatility on these markets (see Watkins and McAleer (2006);Watkins and McAleer (2008)) limiting opportunities for risk reduction. In addition to speculative demand, the prices are also driven by changes in industrial production which makes the analysis of the dynamics of volatility a challenging task. From the earlier papers by Brunetti and Gilbert (1995), Davutyan and Roberts (1994), McMillan and Speight (2001), that analysed the volatility of non-ferrous metals traded on the LME over the period from 1972-1995, it becomes evident that: (i) the volatility has been increased due to the intensified speculative interest in metals from 1993 to 1995; (ii) the prices have demonstrated some degree of cyclicality; (iii) the metals volatility 
should be decomposed to both long-run and short-run components since they are affected by different broad factors, i.e. speculative pressure and fundamental influence. The subsequent literature further augmented these findings.

For example, the study by Roberts (2009) expanded the analysis of the cyclicality of metal prices using monthly prices for 14 metals from January 1947 till December 2007. The results reject the position that metals prices follow random walk demonstrating some regularity and cyclicality, however, the Roberts further claim that cycles are not fully predictable. Watkins and McAleer (2008) forecast the volatility process for daily returns on the metal futures prices using the AR(1)-GARCH $(1,1)$ model using data from 1 October 1982 to 24 July 2006 and from 5 January 1976 to 24 July 2006 for aluminium and copper respectively. While the results confirm the time-varying nature of volatility, the forecasting performance is found to be weaken during the crisis shocks like October 1987 market crash. The study by Lien and Yang (2008) investigated different hedging strategies on aluminium and copper focusing on futures traded at Shanghai Futures Exchange. The results show that the basis has asymmetric effects, i.e. the markets behave differently when the basis is positive or negative. The research by Todorova (2015) analysed the dynamics of realised volatility in the LME non-ferrous metals over the period from January 2004 to September 2012 highlighted an increasing importance of short-term volatility components and superior forecasting ability of a simple HAR model over its augmented versions.

The increased investment interest in commodities in general, and specifically in metals, make these markets highly relevant for theoretical investigation of spillover effect, contagion phenomenon, and portfolio formation. There is some existing, limited research on return or level spillovers. Thus, both Li and Zhang (2013)), Hua and Chen (2007) examine copper and aluminum markets, finding significant bivariate linkages between the Shanghai Futures Exchange and the LME, but with the LME greatly dominant. Li and Zhang (2013)) find that while the LME is still dominant this is slowly fading. Within a category, copper and brass (which has copper as a major component), Aruga and Managi (2011) finds that there is surprisingly little linkage. Sensoy et al. (2015) suggests coordination and convergence in base (and precious) metals while Singhal and Ghosh (2016) also suggests limited feedback from these metals to Indian equity indices.

When we commence looking at spillovers in volatility there is a dearth of research. As discussed in Chevallier and Ielpo (2013) and Todorova et al. (2014) there is a large literature on volatility spillovers in agricultural commodities, energy and precious metals but much less on industrial metals. Using the methods of Diebold and Yilmaz $(2009,2012)$ they find little evidence of spillovers, examining high frequency spillovers between aluminium, copper, lead, nickel, and zinc futures on the LME. Todorova et al. (2014) find that there is multidirection aluminium spillover from cash to futures volatility and within metals from one to another. Nonetheless there is surprisingly little research as yet in this area. In this paper we examine cash prices from the LME, for aluminum, aluminum alloy, copper, lead, nickel, and zinc, over the 1994-2016 period. By contrast with Todorova et al. (2014) who examined the 2006-2012 period this allows us a much longer run perspective. 


\section{Methodology}

\subsection{Data}

We collect closing cash (spot) data on non-ferrous metal contracts offered by the London metal Exchange. We examine data for aluminium, aluminium alloy, copper, lead, nickel, tin and zinc. These metals represent the most important non-ferrous metals in industrial use, where aluminium is the mostly used one, while the second and the third highest usages are for copper and zinc (Boulamanti and Moya (2016b)). We collected daily data for the period from 12 January 1994 to 19 October 2016. For return spillovers analysis we estimate weekly returns as $R_{t}=\ln \left(P_{1} / P_{0}\right)$ where $P_{1}$ is price at the end of the trading week, while $P_{0}$ is the closing price on the first trading day of this week, which gives 1189 observations in total. For volatility spillovers analysis we use two different volatility measures, i.e. squared volatility measure and Parkinson range volatility estimator, that specified by Eqs. 1 and 2 below:

$$
\begin{gathered}
\sigma_{S Q}^{2}=\ln \left(\frac{c}{o}\right)^{2} \\
\sigma_{P}^{2}=\frac{1}{4 \ln 2}(h-l)^{2}
\end{gathered}
$$

Where o, h, l, and c are normalised opening, high, low, and closing prices respectively. The advantages of the range volatility estimators in analysis of the volatility spillovers are discussed in Yarovaya et al. (2016b). Summary statistics for returns and volatilities is shown in Table 1. Table 1 reports that the mean, median, maximum, minimums and standard deviation are higher for Parkinson volatility than squared volatility. However, in comparison to Parkinson, squared volatility estimates have higher values of both skewness and kurtosis. Particularly, nickel and tin have the highest positive skewness and kurtosis in the sample, which indicate the large number of extreme values in squared volatility series, which can potentially cause overestimation of intensity of volatility spillovers using this volatility measure.

\subsection{Spillover Index}

This study employs the Diebold and Yilmaz (2012) (DY) framework to measure the dynamics and the intensity of information transmission across prices on global metal markets. The DY framework is based on a generalized vector autoregressive (VAR) model and has been actively employed in the finance literature to investigate spillover effects across various financial markets (Diebold and Yilmaz (2009) Batten et al. (2014); Yarovaya et al. (2016a)). However, to the best of our knowledge this methodology has not yet been applied to metal data or to analysis of metal markets.

The spillover index approach allows presenting the empirical results in the forms of spillover tables and spillover plots, visualizing the channels and the dynamics of information transmission across markets. Furthermore, the DY framework provides clear evidence on net-contributors and net-recipients of information on non-ferrous metals markets. The DY framework can be described as follows.

Consider a covariance stationary N-variable VAR (p), $X t=\sum_{i=1}^{p}=\Psi_{i} X_{t-i}+\varepsilon_{t}$, where $\Psi_{i}$ is a parameter matrix, and $\varepsilon \sim(0 ; \Sigma)$ is a vector of independently and identically distributed disturbances. The VAR model can be transformed into a moving average (MA) representation, $X_{t}=\sum_{i=o}^{\infty} A_{i} \varepsilon_{t-i}$, where $A_{i}$ is ans $N \times N$ identity matrix $A_{i}=\Psi_{1} A_{i-1}+\Psi_{2} A_{i-2}+\ldots \Psi_{p} A_{i-p}$ beign an $N \times N$ identity 
matrix and with $A_{i}=0$ for $i<0$. The DY framework relies on the N-variable VAR variance decompositions and allows for each variable $X_{i}$ to be added to the shares of its H-step-ahead error forecasting variance, associated with shocks in relevance to variable $X_{j}$ (where $\forall_{i} \neq j$ for each observation). This methodology provides the evidence of information spillovers from one market to another. Besides detecting of cross variance shares, the DY framework defines own variance shares as the fraction of the H-step ahead error variance in predicting $X_{i}$ due to shocks in $X_{i}$. Following Diebold and Yilmaz (2012) the methodological framework employed in this paper relies on KPPS H-step-ahead forecast errors, which are invariant to the ordering of the variables in comparison to the alternative identification schemes like that based on Cholesky factorization (Diebold and Yilmaz (2009)) and can be defined for $H=[1,2 \ldots+\infty)$, as:

$$
\vartheta_{i j}^{g}(H)=\frac{\sigma_{j j}^{-1} \sum_{h=0}^{H-1}\left(e_{i}^{\prime} A_{h} \Omega e_{j}\right)^{2}}{\sum_{h-0}^{H-1}\left(e_{j}^{\prime} A_{h} \Omega A_{h}^{\prime} e_{i}\right)}
$$

where $\Omega$ is the variance matrix for the error vector $\varepsilon ; \sigma_{j j}$ is the standard deviation of the error term for the $j$ th equation; $e_{i}$ is the selection vector, with one as the $i$ th element and zero otherwise. The sum of the elements in each row of the variance decomposition $\sum_{j=1}^{N} \vartheta_{i j}^{g}(H)$ is not equal to 1 . The normalization of each entry of the variance decomposition matrix by the row sum can be defined as:

$$
\tilde{\vartheta}_{i j}^{g}(H)=\frac{\vartheta_{i j}^{g}(H)}{\sum_{j=1}^{N} \vartheta_{i j}^{g}(H)}
$$

where $\sum_{j=1}^{N} \tilde{\vartheta}_{i j}^{g}(H)=1$ and $\sum_{i, j=1}^{N} \tilde{\vartheta}_{i j}^{g}(H)=N$.

The total volatility contributions from KPPS variance decompositions are used to calculate the Total Spillover Index (TSI):

$$
T S I(H)=\frac{\sum_{i, j=1, i \neq j}^{N} \tilde{\vartheta}_{i j}^{g}(H)}{\sum_{i, j=1}^{N} \tilde{\vartheta}_{i j}^{g}(H)} \times 100=\frac{\sum_{i, j=1, i \neq j}^{N} \tilde{\vartheta}_{i j}^{g}(H)}{N} \times 100
$$

We also estimate Directional Spillover Indices (DSI) to measure spillovers from market $i$ to all markets $j$, as well as the reverse direction of transmission from all markets $j$ to market $i$, using equations (4) and (5), respectively:

$$
\begin{aligned}
& D S I_{j \leftarrow i}(H)=\frac{\sum_{i, j=1, i \neq j}^{N} \tilde{\vartheta}_{j i}^{g}(H)}{\sum_{i, j=1}^{N} \tilde{\vartheta}_{i j}^{g}(H)} \times 100 \\
& D S I_{i \leftarrow j}(H)=\frac{\sum_{i, j=1, i \neq j}^{N} \tilde{\vartheta}_{i j}^{g}(H)}{\sum_{i, j=1}^{N} \tilde{\vartheta}_{i j}^{g}(H)} \times 100
\end{aligned}
$$

Finally, we explore who are the net-contributors and net-recipients of information on international non-ferrous metals market, using the Net Spillover Index (NSI) calculated as the difference between total shocks transmitted from market $i$ to all markets $j$ and those transmitted to market $i$ from all markets $j$ :

$$
N S I_{i j}(H)=\frac{\sum_{i, j=1, i \neq j}^{N} \tilde{\vartheta}_{j i}^{g}(H)}{\sum_{i, j=1}^{N} \tilde{\vartheta}_{i j}^{g}(H)}-\frac{\sum_{i, j=1, i \neq j}^{N} \tilde{\vartheta}_{i j}^{g}(H)}{\sum_{i, j=1}^{N} \tilde{\vartheta}_{i j}^{g}(H)} \times 100
$$




\subsection{Asymmetric causality}

The asymmetry in causal linkages between international prices is assessed using the asymmetric causality test by Hatemi-J (2012) suggested bootstrap simulation technique for calculating of critical values. The approach to transform the data into both cumulative positive and negative innovations was introduced by Granger and Yoon (2002) to test time-series for cointegration. In effect we examine whether or not a series negative or positive innovations show greater causal impact on other series negative or positive innovations.

Assume that two integrated variables $y_{1 t}$ and $y_{2 t}$ are described by the following random walk processes:

$$
y_{1 t}=y_{1 t-1}+\theta_{1 t}=y_{1,0}+\sum_{i=1}^{t} \theta_{1 i}^{+}+\sum_{i=1}^{t} \theta_{1 i}^{-}
$$

and similarly

$$
y_{2 t}=y_{2 t-1}+\theta_{2 t}=y_{2,0}+\sum_{i=1}^{t} \theta_{2 i}^{+}+\sum_{i=1}^{t} \theta_{2 i}^{-},
$$

The cumulative sums of positive and negative shocks of each underlying variables can be defined as follows:

$$
y_{1 t}^{+}=\sum_{i=1}^{t} \theta_{1 i}^{+}, y_{1 t}^{-}=\sum_{i=1}^{t} \theta_{1 i}^{-}, y_{2 t}^{+}=\sum_{i=1}^{t} \theta_{2 i}^{+}, y_{2 t}^{-}=\sum_{i=1}^{t} \theta_{2 i}^{-},
$$

where positive and negative shocks are defined as: $\theta_{1 t}^{+}=\max \left(\Delta \theta_{1 i}, 0\right) ; \theta_{2 t}^{+}=\max \left(\Delta \theta_{2 i}, 0\right) ; \theta_{1 t}^{-}=$ $\min \left(\Delta \theta_{1 i}, 0\right) ; \theta_{2 t}^{-}=\min \left(\Delta \theta_{2 i}, 0\right)$.

To test the causalities between these components vector autoregressive model of order $\mathrm{p}$, VAR (p) is used:

$$
y_{t}^{+}=v+A_{1} y_{t-1}^{+}+\ldots+A_{p} y_{t-1}^{+}+u_{t}^{+},
$$

where $y_{t}^{+}=\left(y_{1} t^{+}, y_{2} t^{+}\right)$is the $2 \times 1$ vector of the variables, $v$ is the $2 \times 1$ vector of intercepts, and $u_{t}^{+}$is a $2 \times 1$ vector of error terms (corresponding to each of the variables representing the cumulative sum of positive shocks); $A_{j}$ is a $2 \times 1$ matrix of parameters for lag order $\gamma(\gamma=1,, p)$. The information criterion (HJC) suggested by Hatemi-J (2003) is used to select the optimal order $(p)$ :

$$
H J C=\ln \left(\left|\hat{\Omega}_{j}\right|\right)+j\left(\frac{n^{2} \ln T+2 n^{2} \ln (\ln T)}{2 T}\right),
$$

where $j=0, \ldots, p ;\left|\hat{\Omega}_{j}\right|$ is the determinant of the estimated variance-covariance matrix of the error terms in the VAR model based on the lag order $j, n$ is the number of equations in the VAR model and $T$ is the number of observations.

This information criterion was tested by Hatemi-J (2008). The simulation experiments confirmed the robustness of this criterion to ARCH effect, which is important for this paper due to the existence of heteroskedasticity in the data. The next step of the analysis is to test the Null Hypothesis that $k$ th element of $y_{t}^{+}$does not Granger-cause the $\omega$ th element of $y_{t}^{+}$using the Wald test methodology. 


\subsection{Wavelet Coherence}

In this paper we also employ the wavelet coherence method to further unveil the investors' behaviour in non-ferrous markets. Both a generalised VAR and asymmetric causality test are unable to detect the difference in co-movements at low and high frequencies, the wavelet coherence framework allow us to describe co-movements in time-frequency domain. The wavelets is a powerful tool to explore the behaviour of investors with short-, medium- and long-term investment strategies. This method has been employed by Hkiri et al. (2018) in analysis of interconnections between U.S. financial CDS spread and major global factors including the US stock market volatility, Libor, Treasury bill rates, and oil price. Vacha and Barunik (2012) applied wavelet approach to commodity market data including crude oil, gasoline, heating oil, and natural gas. Cai et al. (2017) also used the wavelet coherence analysis to examine interdependence between oil and East Asian stock markets, while Pal and Mitra (2018) employed wavelet coherence framework to analyse oil price and automobile stock return co-movement. However, just a few paper to date employed the wavelet coherence framework for non-ferrous markets research. For example, Kriechbaumer et al. (2014) assessed the usefulness of an improved combined wavelet-autoregressive integrated moving average approach for forecasting monthly prices of aluminium, copper, lead and zinc. To our best knowledge, our study is the first empirical study that employed wavelet coherence framework to assess the interconnectedness between the non-ferrous metals markets.

Wavelet multi-resolution analysis decomposes a time series through application of a wavelet $\psi(t)$ which is a function of a time parameter $t$. The wavelet function provides a balance between localization of time and scale. Given a time series $f(t)$ expressed over the interval $[-\alpha<t<\alpha]$, the set of wavelet coefficients $W(\tau, \epsilon)$ is given by

$$
W(\tau, \epsilon)=\sum_{t=1}^{N} f(t) \psi^{*}\left[\frac{t-\tau}{\epsilon}\right]
$$

where $[\epsilon>o ;-\alpha<\tau<\alpha]$, and the scale associated with the transformation and location of the window are defined by $\epsilon$ and $\tau$ respectively. $\psi^{*}$ and $\frac{1}{\epsilon}$ refer to the complex conjugate of the wavelet and the normalization factor respectively. In our application, we choose the Morlet wavelet, due to its strong localization properties. ${ }^{2}$ The Morlet wavelet is the product of a sine curve with a Gaussian and given by

$$
\psi(t)=\pi^{\frac{1}{4}}\left(e^{i \omega_{0} t}-e^{-\frac{\omega_{0}^{2}}{2}}\right) e^{\frac{-t^{2}}{2}}
$$

where $\omega_{0}$ is the wavenumber. For an appropriate choice of the wavenumber $\omega_{0}$ the Morlet wavelet reduces to

$$
\psi(t)=\pi^{\frac{1}{4}} e^{i \omega_{0} t} e^{\frac{-t^{2}}{2}}
$$

We now define a number of metrics which assist a time-scale (horizon) understanding of financial and economic time series, and which are based upon the wavelet transform. The wavelet power spectrum allows characterisation of the spectral energy (variance) of a time series across both time and scale (frequency). ${ }^{3}$ This results in a two dimensional distribution, giving localised information

\footnotetext{
${ }^{2}$ Alternative wavelet forms were additionally tested, but resulted in no qualitative changes to findings.

${ }^{3}$ The literature on wavelets equivalently refers to the scale, period and horizon associated with the decomposition, each of which may be interpreted as the wavelength. The inverse of the wavelength is the frequency, measuring the
} 
pertaining to the variance of the signal for a particular scale at a given point in time. The wavelet power spectrum for a series $f(t)$ is simply the square of the wavelet coefficient at a given scale and point in time, $\left|W_{\lambda, \tau}^{2}(x)\right|$. The statistical significance of wavelet power may be measured versus the null hypothesis of an $\mathrm{AR}(0)$ (white noise) or AR(1) (red noise) process Torrence and Compo (1998). The corresponding distribution for the wavelet power spectrum is the chi-squared distribution AguiarConraria et al. (2008). The area corresponding to wavelet coefficients influenced by border effects is known as the 'cone of influence', and is shown by a light black line in plots.

The cross-wavelet power spectrum is the product of the wavelet coefficients calculated using $W_{\epsilon, \tau}(f, g)=W_{\epsilon, \tau}(f) * W_{\epsilon, \tau}(g)$, where $*$ is defined as a complex conjugate. In common with the conventional, non-spectral measure of covariance, the magnitude of the cross-wavelet power can also be influenced by the variance of each series. In order to ensure a spectral measure of comovement which is comparable across time series, many studies (e.g., Kriechbaumer et al. (2014); Aloui et al. (2016)) use the wavelet coherence framework, calculated as the smoothed cross-wavelet spectrum, normalized by the smoothed wavelet power spectra,

$$
\rho_{\epsilon, \tau}^{2}=\frac{\left|Q\left(\epsilon^{-1} W_{\epsilon, \tau}(f, g)\right)\right|^{2}}{\left.\left.Q\left(\mid \epsilon^{-1} W_{\epsilon, \tau}(f)\right)\right|^{2} Q\left(\mid \epsilon^{-1} W_{\epsilon, \tau}(g)\right)\right|^{2}}
$$

where $Q$ refers to a smoothing operator in both time and scale (Torrence and Compo (1998)). Wavelet coherency is analogous to squared correlation, measuring the co-variation between two series divided by their variation at different scales and points in time. The value of the squared coherency $\rho_{\epsilon, \tau}^{2}$ is between zero (low level of synchronization or zero co-movement) and one (strong synchronization or perfect co-movement). With this approach, the graphical presentation of the wavelet squared coherence enables us to identify the "region" of co-movement between inflation and gold returns in the time-scale space. The theoretical distribution of wavelet coherency is not known and Monte-Carlo methods are invoked to determine statistical significance (Aguiar-Conraria et al. (2008)).

The level of wavelet coherence provides information relating to the synchronization between two time series but does not indicate whether this relationship is positive or negative. To understand the form of synchronization between two time series, the wavelet multi-scale phase is employed. For two time series $f(t)$ and $g(t)$ this is given by

$$
\theta_{\epsilon, \tau}(f, g)=\tan ^{-1}\left(\frac{\Im\left\{Q\left(\epsilon^{-1} W_{\epsilon, \tau}(f, g)\right)\right\}}{\Re\left\{Q\left(\epsilon^{-1} W_{\epsilon, \tau}(f, g)\right)\right\}}\right)
$$

where $\Im$ and $\Re$ refer to the imaginary and real parts of the wavelet coefficients respectively and $Q$ is the smoothing parameter.

\section{Empirical Results}

\subsection{Market integration indices}

Table 2 reports input-output decompositions of spillovers indices for the seven non-ferrous metals selected for this study. ${ }^{4}$ Table 3 and Table 4 demonstrate the results of volatility spillovers analysis

\footnotetext{
number of cycles per period.

${ }^{4} \mathrm{The} i j^{t h}$ entry is the estimated spillover contribution to the forecast error variance of market $i$ from shocks emanating from market $j$. The results in the row Contribution to others demonstrate the returns on which of the metals is the most
} 
for Parkinson volatility and square volatility respectively. There are several observations that can be made based on the results reported in the spillovers tables.

First, similarly to the previous studies which have used the Diebold and Yilmaz (2012) approach, we find that the value of TSI is higher for returns as compared to volatility, which is evident for both volatility measures used. Particularly, TSI for returns equal 60\% (cumulative contributions from others/cumulative contributions to others), while for the Parkinson volatility estimator the value of TSI is $43.9 \%$ and for the squared volatility estimator it is $49.1 \%$. Comparing the findings obtained for two different volatility measures used in this study we can see a lack of consistency in the results for all net, pairwise and directional spillovers indices. However, apart from the values of TSI other results do not provide evidence that the squared volatility measure leads to an overestimation of intensity of volatility spillovers. Indeed, in many cases the findings suggest a reverse conclusion.

Second, the results indicate that the main sources of return spillovers are aluminium, copper and zinc since they have the highest values of contribution to others $77.04 \%, 74.12 \%$ and $73.76 \%$. Furthermore, these metals have positive values of NSI, i.e. the difference between contribution to and from equal $11.07 \%, 9.11 \%$, and $8.58 \%$ for aluminium, copper and zinc respectively, Therefore, the conclusion can be drawn that aluminium, copper and zinc are the net-transmitter/net-contributors of return spillovers. Alternatively, alloy, lead, nickel, and tin are found to be a net-recipients, with values NSI equal $-7.17 \%,-4.35 \%,-7.21 \%$ and $-10.04 \%$ respectively. In respect of volatility transmission, the results are highly sensitive to the choice of volatility estimator. For example, for the Parkinson volatility measure the spillover analysis indicate the net-contributors are aluminium, copper, lead and zinc, but for Squared volatility the results suggest an alternative conclusion the net-contributors are alloy, copper and zinc, which do not allow to robustly argue who are the net-transmitter/recipients of volatility across selected metals.

Overall, the results reported in all Tables confirm the role of copper and zinc are the main stresstransmitters. Alternatively the spillover analysis indicate that nickel and tin have the highest values of DSI from others and also NSI, which makes these metals the net-recipients of both returns and volatility spillovers.

Figure 2 plots the total spillovers across non-ferrous metals using rolling window approach for the whole estimation period for returns (a), Parkinson (b) and Squared (b) volatility measures. Figure 2 shows several similar patterns, i.e. upward/downward trends in total spillovers, during the period from 12 January 1994 to 19 October 2016. There are three downward trends identified: (i) Q4 1995-Q4 1998; (ii) Q4 2002-Q2 2007; (iii) Q1 2014-Q4 2016. Besides, we can see 2 periods of increase in to total return spillovers, i.e. upward trends: (i) Q1 1999-Q3 2002; (ii) Q3 2007-Q4 2013. Similar patterns are identified for volatility spillovers, however, the final downward trend in volatility spillovers has started earlier in comparison to returns, i.e. from Q2 2012 - Q4 2016. It appears that connectedness across markets increases during times of recessions, most prominently the Great Recession of 2007-

influencial in the sample, while the column From others shows the metals who are the-most affected by the information transmitted from other markets in the sample. In order to further highlight the net-contributors and net-recipient of return spillover we follow Yarovaya et al. (2016a) and expand the DY (2009, 2012) spillover tables by adding the column Net which include the values of the Net Spillover Indices (see Eq. 8). A conclusion is provided in the final column Conclusion. A similar approach is used for Table 3 and Table 4 design. 
2009, and then, connectedness decreases during the following recovery periods. While a more articulate explanation of this phenomenon would require a separate and thorough analysis, we believe one reason we observe this pattern could be related to the fact that similar traders take positions in stock and commodity markets. As discussed by Kyle and Xiong (2011) and Buyuksahin and Robe (2011), among others, in recessions stock markets tend to be in bear markets, traders in equity markets face borrowing constraints and sundry pressures to liquidate risky positions. This likely causes them to exit from secondary (or satellite) markets such as commodities at the same time. Since investors tend to act similarly in all commodity markets together, this increases information flows and hence, causes upward movements in connectedness between these markets that we observe in our study. Figure 3, 4 and 5 further explain the dynamics of the directional spillovers across selected non-ferrous metals over the estimation period for three measures. Findings are consistent for returns, Parkinson and squared volatility measures.

\subsection{Wavelet Coherence}

The wavelet method is a suitable method to analyse the interlinkages between time series across different frequencies and time-scales. The cross wavelet power reveals the areas in the time scale when two time series have high level of co-movements. Thus, we use the wavelet coherence to provide further evidence on co-movements between non-ferrous metal markets, measuring the local correlation in time and scale. Apart from the high power areas, the wavelet coherence plots display areas where a selected pair of metals also co-moves, but do not demonstrate high power, i.e. these regions indicate contagion effect. Therefore, by employing this technique, we can also enrich the evidence on pairwise spillovers across selected metal markets, with a help of the phase arrows. ${ }^{5}$

Shown in Fig 6 - 10 are wavelet coherence plots (WCP) for each metal against each other. In the WCP the horizontal axes refer to time intervals, while the vertical axes refer to frequency bands. The red colours of WCP indicate the areas of high power, i.e. high degree of co-movements between markets. Thus, a general observation that can be made from Fig $6-10$ is that the strength of relationships is generally stronger at high frequency bands, since these red areas are appeared at the bottom of the coherence plots. However, the presence of coloured areas at the top of the WCP suggest the existence of co-movements in lower frequencies too. Therefore, in general all market-pairs are characterised by high degree of co-movements.

More specifically, Figure 6 presents the WCP for pairs of aluminium with other markets. We can see that aluminium aluminium alloy (Fig. 6a) and aluminium copper (Fig 6b) demonstrate the highest degree of co-movement at all frequencies and during whole timespan. However, in comparison with other pairs (Fig. 6c-f), we can see that Fig. 6 a and Fig. 6b show especially strong co-movements at high-frequencies, i.e. $64-256$, over the whole sample. The impact of the crisis periods, that identified in previous section by DY spillover plots, is not visible in the WCPs for these two market pairs, however,

\footnotetext{
${ }^{5}$ The phase arrows indicate the direction of co-movement among the investigated series pairwise. East (west) facing arrows represent in- (out-of-) phase, while north (south) facing arrows indicate that time series two leads (lags) time series one. A north-east (south-east) facing arrow symbolizes that the series are in-phase but that time series two (time series one) leads time series one (time series two). A north-west (south-west) facing arrow signifies that the series are out-of-phase but that time series one (time series two) leads time series two (time series one).
} 
it rather pronounced for aluminium lead, aluminium - nickel, aluminium - tin and aluminium zinc pairs (Fig. 6c-f). For example, for aluminium tin pair the WCP show the increased in co-movements after the global financial crisis (Fig. 6e).

Similar findings are presented in Fig. 7-10 for other combinations of the selected non-ferrous metals. The higher power-regions reside in the middle of the sample period at high frequencies, and at the end of the period at both low and high frequencies. This indicate that co-movements between metals markets has increased over time. For many pairs (e.g. alloy-copper, alum. alloy -zinc, copper lead, lead-zinc) we can argue that the linkages between markets are intensified after the global financial crisis which indicate the presence of contagion effect across these markets.

The phase arrows show that these markets have erratic behaviour, since the direction of the arrow varies across time-frequency bands. However, a general observation about lead-lag relationships between markets that can be made from Fig. 6 that at higher frequencies the arrows are south-east facing, i.e. aluminium leads the other markets, however, at lower frequencies the arrows are north-east facing, i.e. the price of aluminium is driven by the changes in prices on other metals. The results previously reported in the spillover tables demonstrated that aluminium is one of the main contributors of both return and volatility spillovers to other markets. Therefore, based on the wavelets analysis, we can further argue that the role of aluminium as net-transmitter of shocks is mainly due to the high degree of co-movements at high-frequencies with other markets during the overall time span.

The other metals that are found to be net-contributors in previous section are copper and zinc. The application of wavelets methodology to all combinations for copper and zinc supports these findings - Figures 6-10 support this but not however, in all time-frequencies bands. Thus, copper is found to lead aluminium, tin and lead at lower frequencies after the global financial crisis, while alloy, nickel, and zinc at higher frequencies during the whole estimation period. Similar patterns are identified for zinc; thus, for zinc-aluminium, zinc-lead, zinc -tin and zinc-copper, zinc is a leading market at lower frequencies after the crisis period, while for zinc-alloy, and zinc-nickel pairs, zinc is leading at higher frequencies throughout the whole observation period. Again, alloy, lead, nickel and tin are found to be recipients of the information by the results of spillover analysis performed in previous section. There is some evidence supporting these results provided by the WCP in Fig. 6-10 since, however, as has been mentioned earlier, the direction of the relationships varies among time and frequencies.

\section{NARDL Results}

The results of a Granger Causality test as described above is provided in Table 5. For brevity we report only the significant results. Lead and tin provide little asymmetric causality, with the majority of influences coming from aluminium and aluminium alloy. The NARDL estimation provides context to the findings elsewhere, as they allow any influences to be decomposed into positive and negative influences. As might be expected positive and negative shocks in both alum. alloy and aluminium granger cause each other, as does lead and zinc, However, it is also clear that in general both alum. alloy and aluminium are the drivers in terms of causality. Aluminium positive shocks are the single largest driver of causality, in eleven cases. Nickel and zinc in contrast are the most open to influence, both being caused by 11 others. Despite contributing little, only two instances, lead (mainly negative) is open to seven causal relationships (five to negative and two to positive). 
We believe the leadership role that we detect for aluminium is driven by two primary factors. Firstly, as Watkins and McAleer (2008) state, changes in aluminium are much more closely aligned with global industrial production than the other commodities in our sample (save for copper). Aluminium is widely used in automobile, construction and aerospace industries. Boulamanti and Moya (2016a) also claim that aluminium is the mostly used metal, while the second and the third highest usages are for copper and zinc. Secondly, as a market micro-structure factor, aluminium is most widely traded contract on the LME. The finance literature states that trading volume is correlated with information flow; hence, this factor also attributes a leadership role to aluminium. Todorova and Clements (2018) analysed the volume-volatility relationships for the five LME futures on aluminium, copper, nickel, lead and zinc, and found that positive shocks in trading volume and negative shocks in the trading frequency are the dominant factors of the volatility-volume relationships. Besides, according to Wu and $\mathrm{Hu}$ (2016) aluminium market is more susceptible to external shocks, and the return of aluminium is the most overvalued, therefore during the recession time when co-movement between markets is increasing, aluminium plays role of the transmitter of volatility to other non-ferrous metals.

\section{Conclusion}

The co-movement analysis between LME metal markets is highly important for asset allocation decision and diversification of the risk. This paper considers the interconnectedness of seven industrial metal prices, i.e. aluminium, aluminium alloy, copper, nickel, lead, tin and zinc, for the period from 1994-2016, using spillover analysis and wavelet coherence framework. This paper provides the supporting evidence to the position that the non-ferrous metals can be considered as a separate investment class, due to the high degree of financial integration between these markets. This study reveals several important observations contributing to the growing field of literature on behavior of the non-ferrous markets.

The results of spillover analysis show the higher degree of spillovers across markets. The identified dynamics of return and volatility transmission revealed the increase in total spillovers across markets during the financial crises. Therefore, we can conclude that the behaviour of the non-ferrous metals is similar to other more conventional asset classes, like equities and bonds, justifying the position that metals have become an investment asset. In this paper, we analysed not only return spillovers, but also volatility spillovers, providing the novel evidence from two volatility estimators (Parkinson range volatility estimator, and squared volatility measure). We found that square volatility measure is demonstrated higher value of kurtosis, that can cause overestimation of intensity of volatility spillovers, while the range volatility estimator provide the results that more consistent with the returns spillovers in respect to intensity, direction and dynamics of spillovers. This contributes to Yarovaya et al. (2016b) who discussed the advantages of the range volatility estimates in spillovers studies. Based on the return and volatility spillover analysis we conclude that aluminium, copper, and zinc are net-transmitters of spillovers, while alloy, nickel, lead and tin are net-recipients.

The results are further verified by using the wavelet coherence approach. The findings suggest the strong degree of co-movements between all non-ferrous markets, however, this co-variation is highly depended on the time and frequency band. Thus, the co-movements between markets are unstable. Furthermore, the lead-lag relationships between pairs of metals show erratic behaviour, 
since they found to be susceptible to time and frequencies. The WCP show highly changing patterns of co-movements, however, for some pairs there are higher co-movements at higher frequencies than at lower-frequencies, for other reverse. These results can be interesting for investors with various investors horizons, with short-term and long-term investments strategies. Besides, the application of the wavelet approach revealed that the high-power regions of wavelet coherence are corresponding to the realworld events, such as the global financial crisis. Thus, we confirm the findings of spillover analysis, that the crisis has increased the degree of co-movements between selected LMEs non-ferrous metals, contributing to contagion literature. For investors seeking to diversify in to alternative investments such as these assets it is vital to recall the real world linkages - these industrial metals are intimately linked to the global economy. It is also important to note that these are not monetary metals- their store of value element is low. This however positions them nicely against metals such as silver and gold. These findings further support the argument that metals have not only industrial role, but also is an investment asset. 


\section{Bibliography}

Aguiar-Conraria, N., N. Azevedo, and M. Soares (2008). Using wavelets to decompose the timefrequency effects of monetary policy. Physica A: Statistical Mechanics and its Applications 387, $2863-2878$.

Agyei-Ampomah, S., D. Gounopoulos, and K. Mazouz (2014). Does gold offer a better protection against losses in sovereign debt bonds than other metals? Journal of Banking $\&$ Finance 40, $507-521$.

Aloui, C., B. Hkiri, C. K. M. Lau, and L. Yarovaya (2016). Investors sentiment and us islamic and conventional indexes nexus: A timefrequency analysis. Finance Research Letters 19, 54-59.

Arezki, R., A. Matsumoto, and H. Zhao (2015). Commodity Special Feature. World Economic Outlook, 15.

Aruga, K. and S. Managi (2011). Price linkages in the copper futures, primary, and scrap markets. Resources, Conservation and Recycling 56(1), 43-47.

Batten, J., C. Ciner, and B. Lucey (2010, jun). The macroeconomic determinants of volatility in precious metals markets. Resources Policy 35(2), 65-71.

Batten, J. A., C. Ciner, and B. M. Lucey (2014, dec). Which precious metals spill over on which, when and why? Some evidence. Applied Economics Letters 22(6), 466-473.

Beckmann, J. and R. Czudaj (2013). The forward pricing function of industrial metal futures-evidence from cointegration and smooth transition regression analysis. International Review of Applied Economics $27(4), 472-490$.

Belousova, J. and G. Dorfleitner (2012). On the diversification benefits of commodities from the perspective of euro investors. Journal of Banking and Finance 36 (9), 2455-2472. cited By 12.

Bosch, D. and E. Pradkhan (2015). The impact of speculation on precious metals futures markets. Resources Policy 44, 118-134.

Boulamanti, A. and J. Moya (2016a). Production costs of the non-ferrous metals in the eu and other countries: Copper and zinc. Resources Policy 49, 241-247.

Boulamanti, A. and J. A. Moya (2016b). Production costs of the non-ferrous metals in the eu and other countries: Copper and zinc. Resources Policy 49, 112-118.

Brunetti, C. and C. L. Gilbert (1995). Metals price volatility, 1972-1995. Resources Policy 21(4), $237-254$.

Cai, X., S. Tian, N. Yuan, and S. Hamori (2017). Interdependence between oil and east asian stock markets: Evidence from wavelet coherence analysis. Journal of International Financial Markets, Institutions and Money 48, 206-223. 
Chevallier, J. and F. Ielpo (2013, sep). Volatility spillovers in commodity markets. Applied Economics Letters 20(13), 1211-1227.

Chinn, M. and O. Coibion (2014). The predictive content of commodity futures. Journal of Futures Markets 34(7), 607-636. cited By 15.

Cummins, M., M. Dowling, and B. M. Lucey (2015). Behavioral influences in non-ferrous metals prices. Resources Policy 45, 9-22.

Delatte, A.-L. and C. Lopez (2013). Commodity and equity markets: Some stylized facts from a copula approach. Journal of Banking \& Finance 37(12), 5346-5356.

Demirer, R., H. T. Lee, and D. Lien (2015). Does the stock market drive herd behavior in commodity futures markets? International Review of Financial Analysis 39, 32-44.

Diebold, F. X. and K. Yilmaz (2009). Measuring Financial Asset Return and Volatility Spillovers, with Application to Global Equity Markets. The Economic Journal 119(534), 158-171.

Diebold, F. X. and K. Yilmaz (2012). Better to give than to receive: Predictive directional measurement of volatility spillovers. 28(1), 57-66.

Dooley, G. and H. Lenihan (2005). An assessment of time series methods in metal price forecasting. Resources Policy 30(3), 208-217.

Erb, C. B. and C. R. Harvey (2006). The strategic and tactical value of commodity futures.

Fernandez, V. (2010). Commodity futures and market efficiency: A fractional integrated approach. Resources Policy 35(4), 276-282. cited By 15.

Fernandez, V. (2016). Futures markets and fundamentals of base metals. International Review of Financial Analysis 45, 215-229.

Geman, H. and M. Scheiber (2014, May). Spot Price Modelling of Industrial Metals An heterogeneous agent based model for Copper. Birkbeck Working Papers in Economics and Finance 1404, Birkbeck, Department of Economics, Mathematics \& Statistics.

Gil-Alana, L. A. and T. Tripathy (2014). Modelling volatility persistence and asymmetry: A study on selected indian non-ferrous metals markets. Resources Policy 41, 31-39.

Gorton, G. and G. K. Rouwenhorst (2006). Facts and fantasies about commodity futures. Financial Analysts Journal 62(2), 47-68.

Granger, C. and G. Yoon (2002). Hidden cointegration department of economics working paper. San Diego: University of California..

Hatemi-J, A. (2008). Tests for cointegration with two unknown regime shifts with an application to financial market integration. Empirical Economics 35, 497-505.

Hatemi-J, A. (2012). Asymmetric causality tests with an application. Empirical Economics 43(1), $447-456$. 
Hkiri, B., S. Hammoudeh, C. Aloui, and M. Shahbaz (2018). The interconnections between u.s. financial cds spreads and control variables: New evidence using partial and multivariate wavelet coherences. International Review of Economics and Finance Forthcoming.

Hua, R. and B. Chen (2007). International linkages of the Chinese futures markets. Applied Financial Economics 17(16), 1275-1287.

Jacobsen, B., B. R. Marshall, and N. Visaltanachoti (2016). Stock market predictability and industrial metal returns.

Kriechbaumer, T., A. Angus, D. Parsons, and M. Casado (2014). An improved waveletarima approach for forecasting metal prices. Resources Policy 39, 32-41.

Li, Z. and L. Zhang (2013). An empirical study of international linkages of the Shanghai Copper Futures Market. Chinese Economy 46(3), 61-74.

Lien, D. and L. Yang (2008). Hedging with Chinese metal futures. Global Finance Journal 19(2), $123-138$.

Liu, Q., M. T. Chng, and D. Xu (2014, 08). Hedging Industrial Metals With Stochastic Volatility Models. Journal of Futures Markets 34(8), 704-730.

Marshall, B., N. Nguyen, and N. Visaltanachoti (2013). Liquidity commonality in commodities. Journal of Banking and Finance 37(1), 11-20. cited By 16.

McMillan, D. G. and A. E. H. Speight (2001). Non-ferrous metals price volatility: A component analysis. Resources Policy 27(3), 199-207.

O'Connor, F. A., B. M. Lucey, J. A. Batten, and D. G. Baur (2015). The financial economics of gold - A survey. International Review of Financial Analysis 41, 186-205.

Omura, A., B. Li, R. Chung, and N. Todorova (2018). Convenience yield, realised volatility and jumps: Evidence from non-ferrous metals. Economic Modelling 70, 496-510.

Pal, D. and K. Mitra (2018). Oil price and automobile stock return co-movement: A wavelet coherence analysis. Economic Modelling Forthcoming.

Roberts, M. C. (2009). Duration and characteristics of metal price cycles. Resources Policy 34(3), $87-102$.

Sensoy, A. (2013). Dynamic relationship between precious metals. Resources Policy 38(4), 504-511.

Sensoy, A., E. Hacihasanoglu, and D. Nguyen (2015). Dynamic convergence of commodity futures: Not all types of commodities are alike. Resources Policy 44, 150-160. cited By 4.

Singhal, S. and S. Ghosh (2016). Returns and volatility linkages between international crude oil price, metal and other stock indices in india: Evidence from var-dcc-garch models. Resources Policy 50, 276-288. cited By 0. 
Todorova, N. (2015). The course of realized volatility in the LME non-ferrous metal market. Economic Modelling 51, 1-12.

Todorova, N. and A. Clements (2018). The volatility-volume relationship in the lme futures market for industrial metals. Resources Policy Forthcoming.

Todorova, N., A. Worthington, and M. Souček (2014). Realized volatility spillovers in the non-ferrous metal futures market. Resources Policy 39, 21-31.

Torrence, C. and G. Compo (1998). A practical guide to wavelet analysis. Bulletin of the American Meteorological Society 79, 61-78.

Vacha, L. and J. Barunik (2012). Co-movement of energy commodities revisited: Evidence from wavelet coherence analysis. Energy Economics 34, 241-247.

Watkins, C. and M. McAleer (2006). Pricing of non-ferrous metals futures on the London Metal Exchange. Applied Financial Economics 16(March 2015), 853-880.

Watkins, C. and M. McAleer (2008). How has volatility in metals markets changed? Mathematics and Computers in Simulation 78(2-3), 237-249.

Wu, D. and Z. Hu (2016). Structural changes and volatility correlation in nonferrous metal market. Transactions of Nonferrous metals Society of China 26, 2784-2792.

Yarovaya, L., J. Brzeszczyński, and C. K. M. Lau (2016a, jan). Intra- and inter-regional return and volatility spillovers across emerging and developed markets: Evidence from stock indices and stock index futures. International Review of Financial Analysis 43, 96-114.

Yarovaya, L., J. Brzeszczyński, and C. K. M. Lau (2016b). Volatility spillovers across stock index futures in Asian markets: Evidence from range volatility estimators. Finance Research Letters 17, $158-166$. 
Figure 1: Price Evolution

Price Evolution

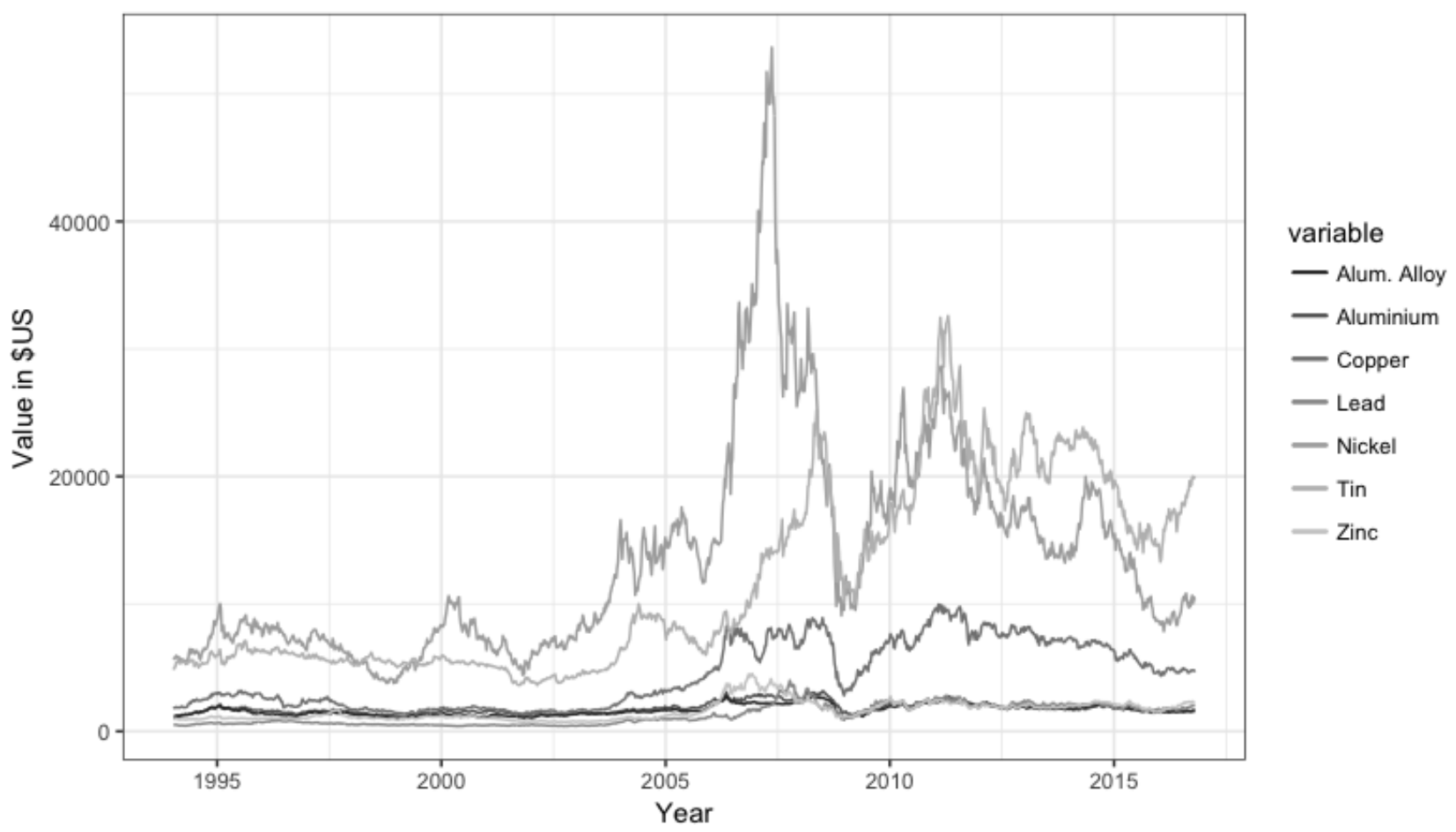


Figure 2: Spillover Plots

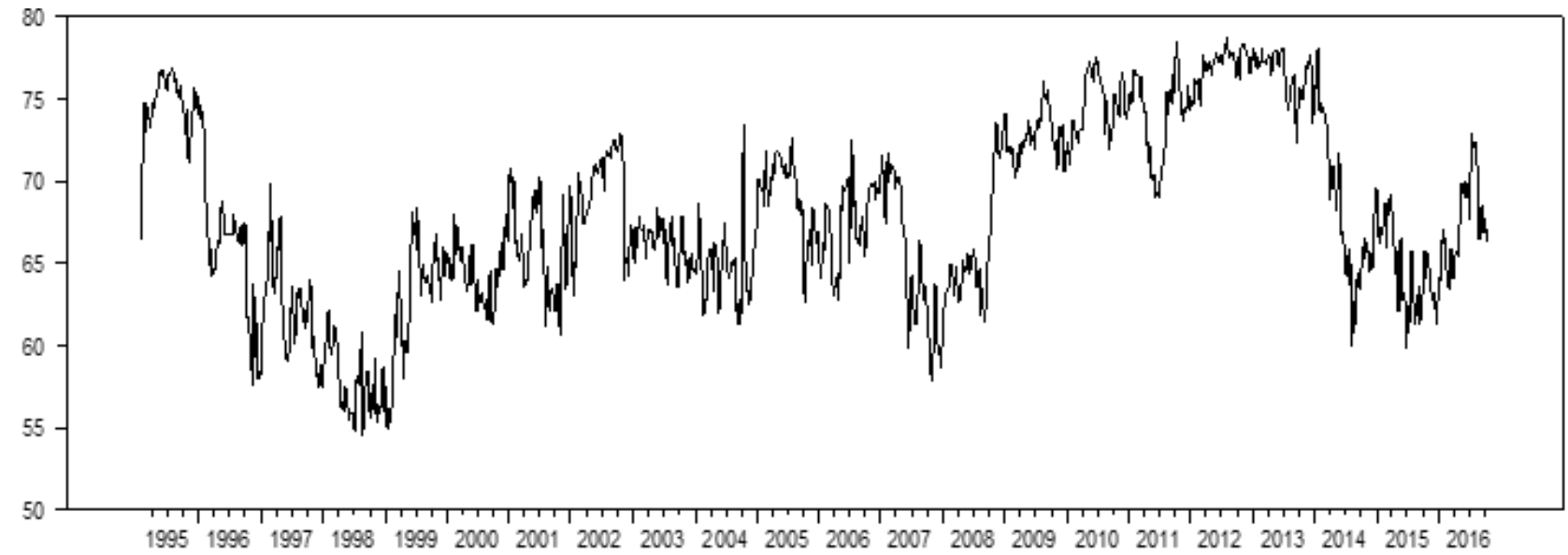

(a) Total Return Spillovers

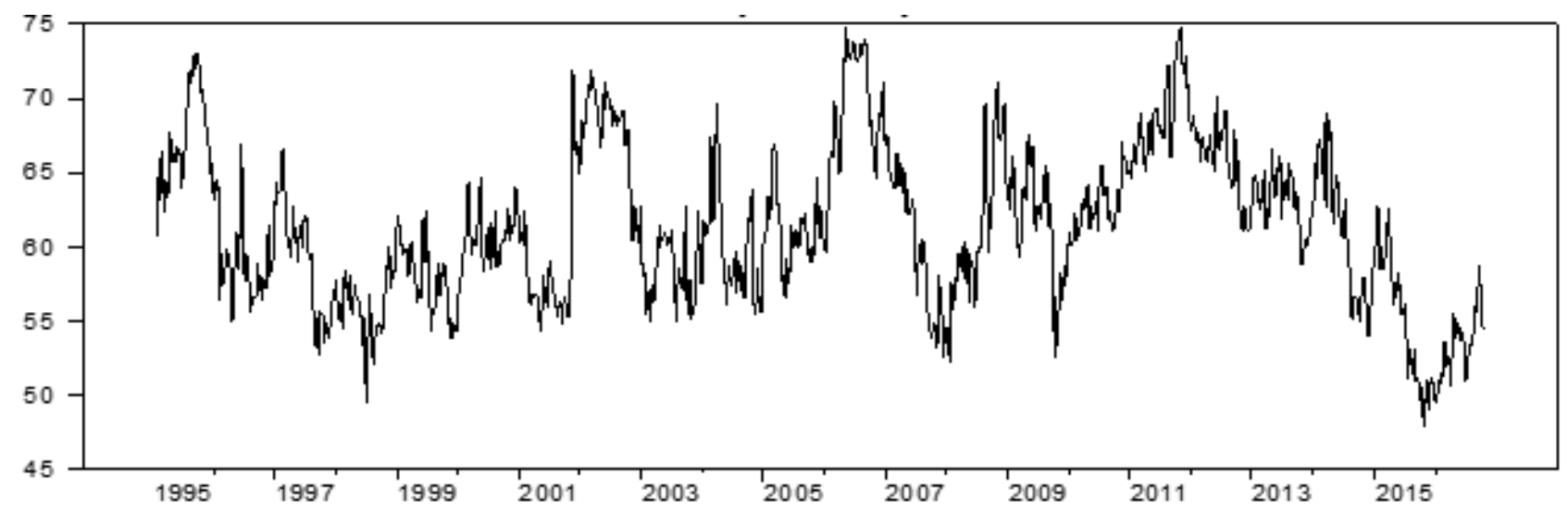

(b) Total Volatility Spillovers

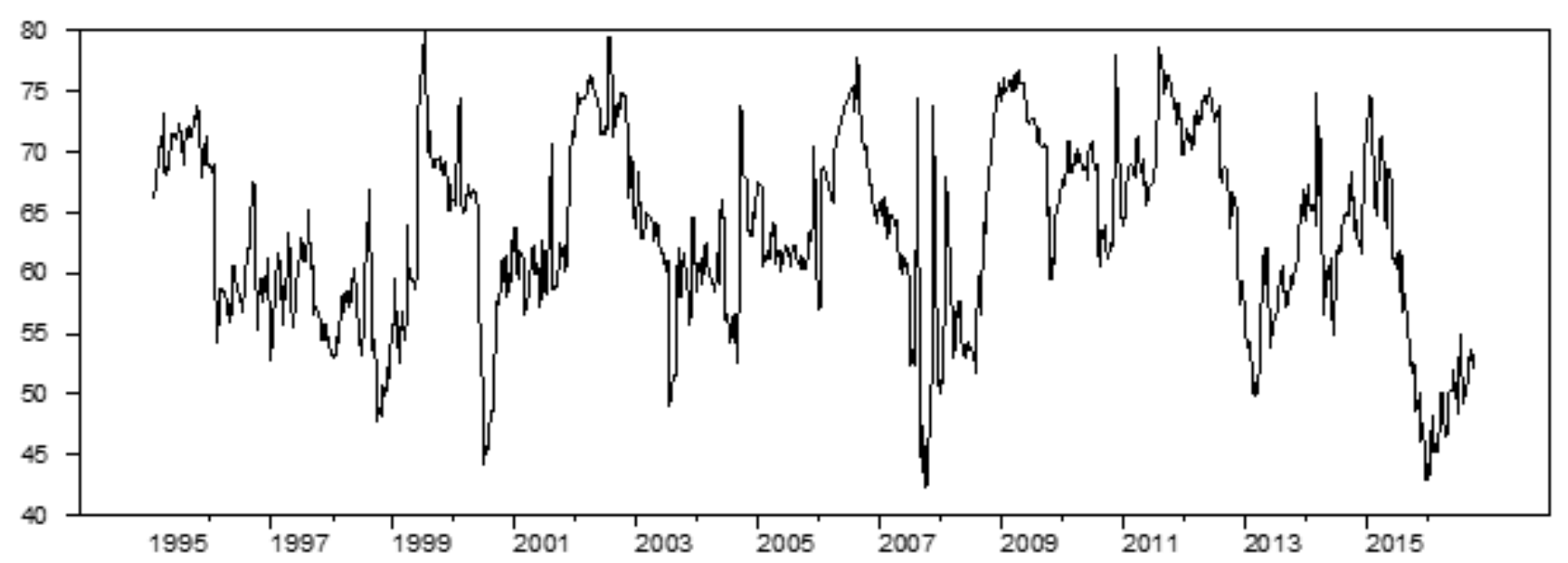

(c) TotAl Squared Volatility Spillovers 
Figure 3: directional Spillovers - Returns
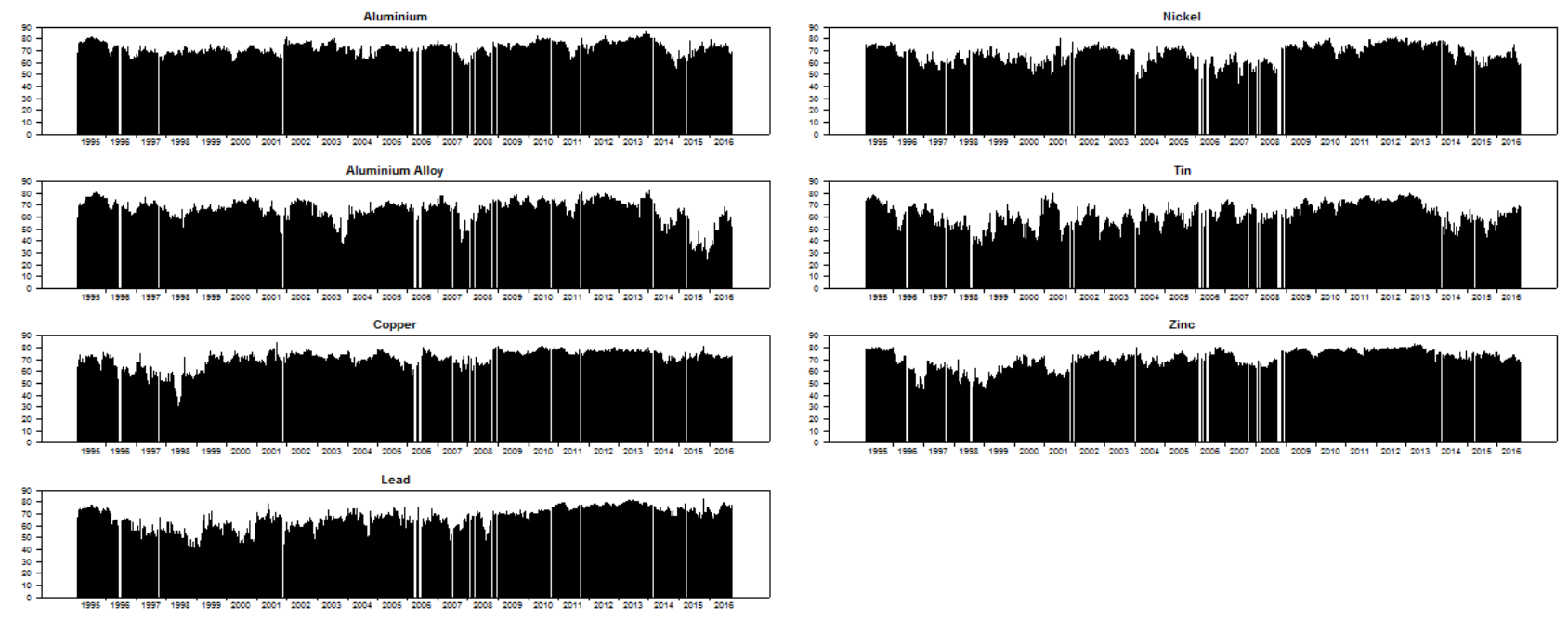

(a) REturn Spillovers Given
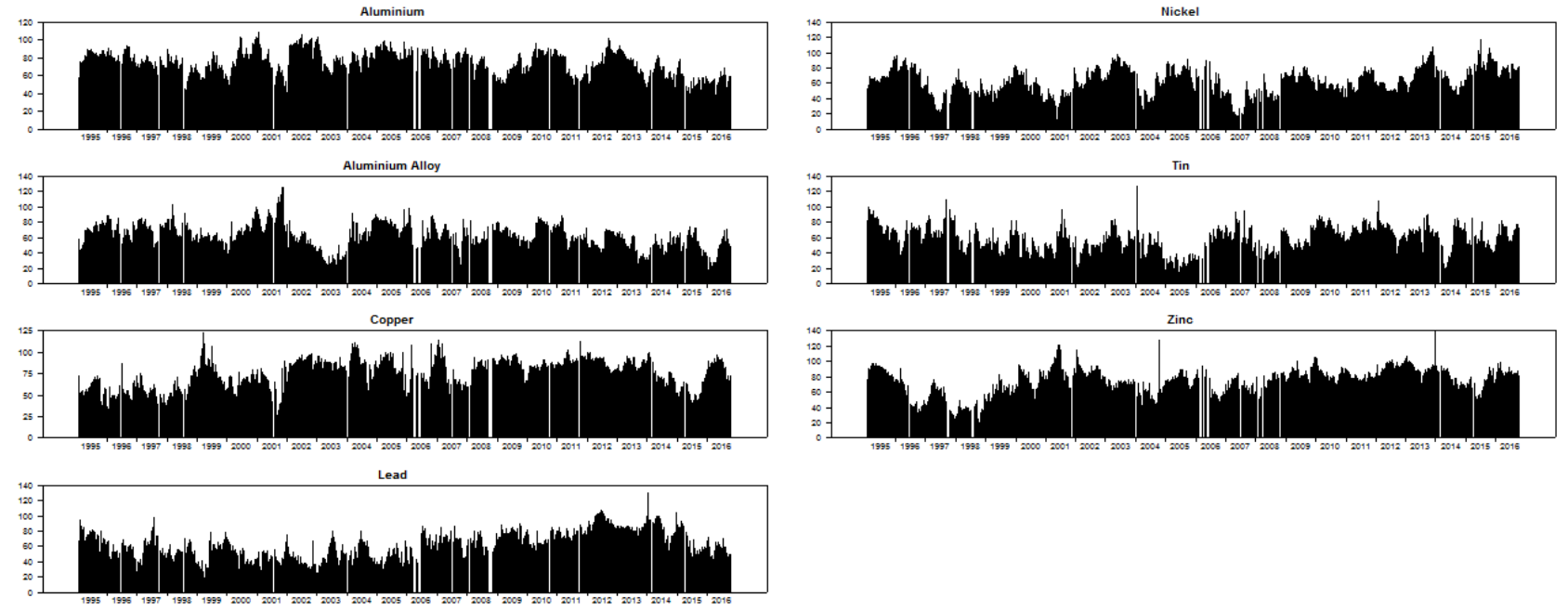

(b) Return Spillovers Received 
Figure 4: directional Spillovers - Volatility
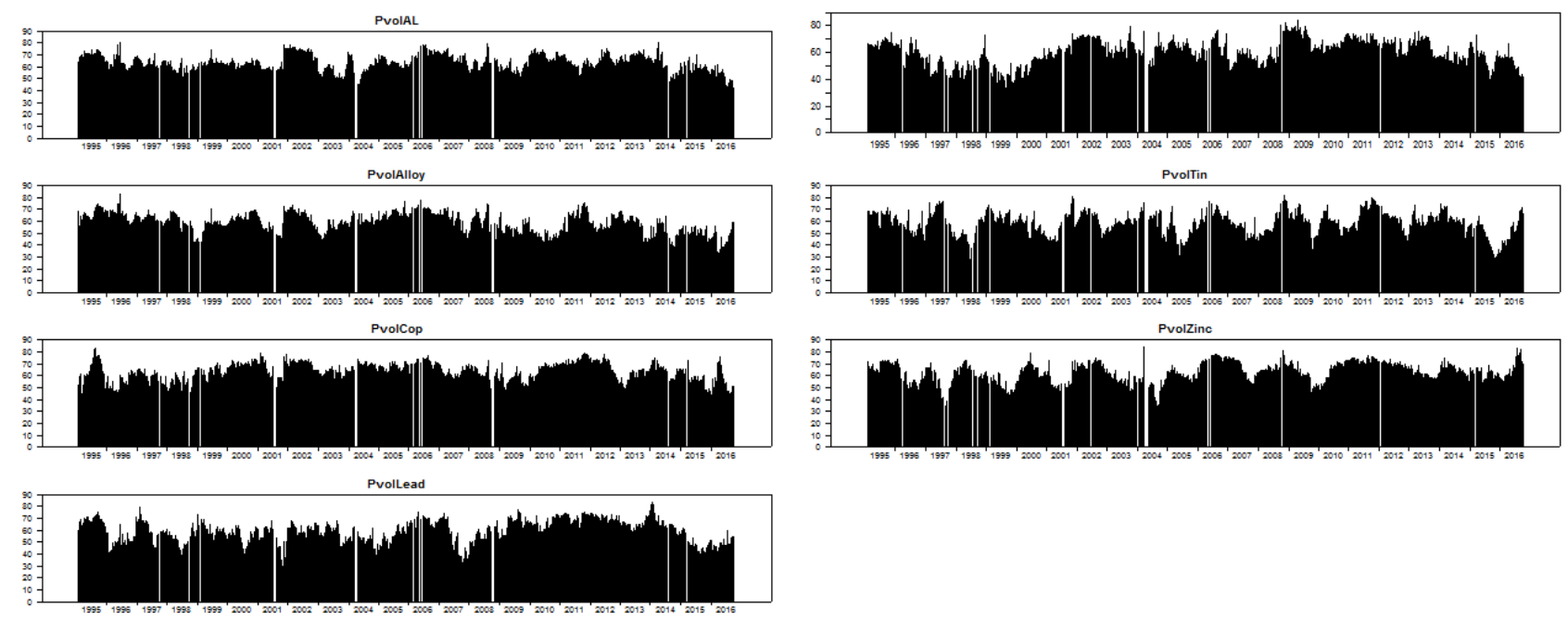

(a) Volatility Spillovers Given
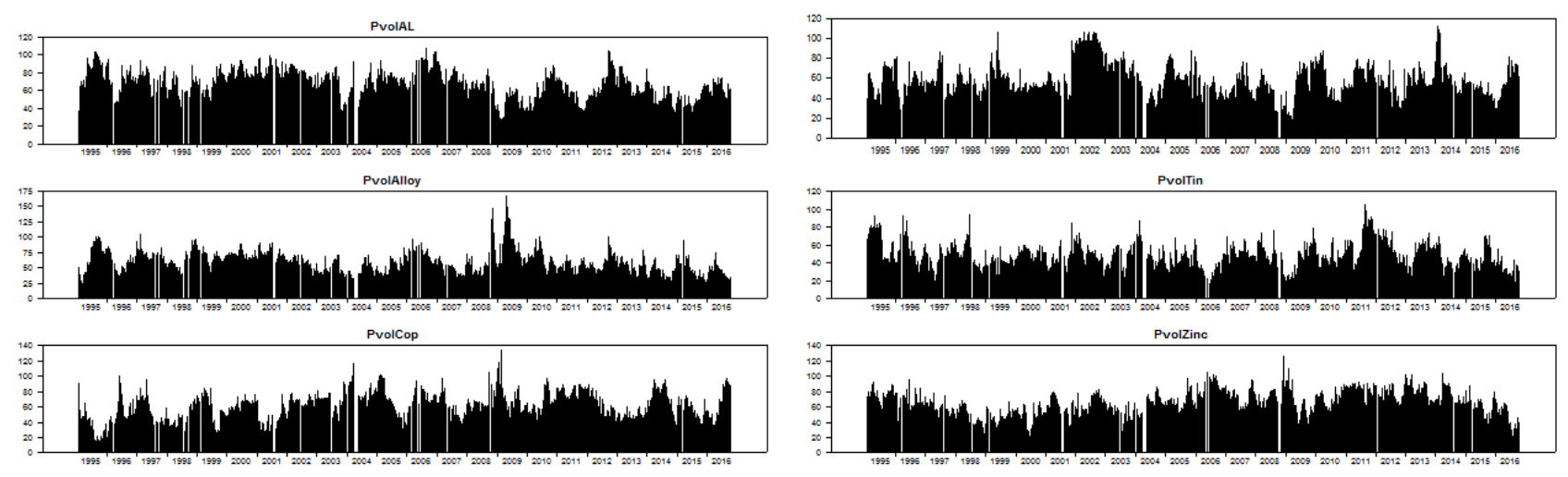

cold

(b) Volatility Spillovers Received 
Figure 5: directional Spillovers - Squared Volatility
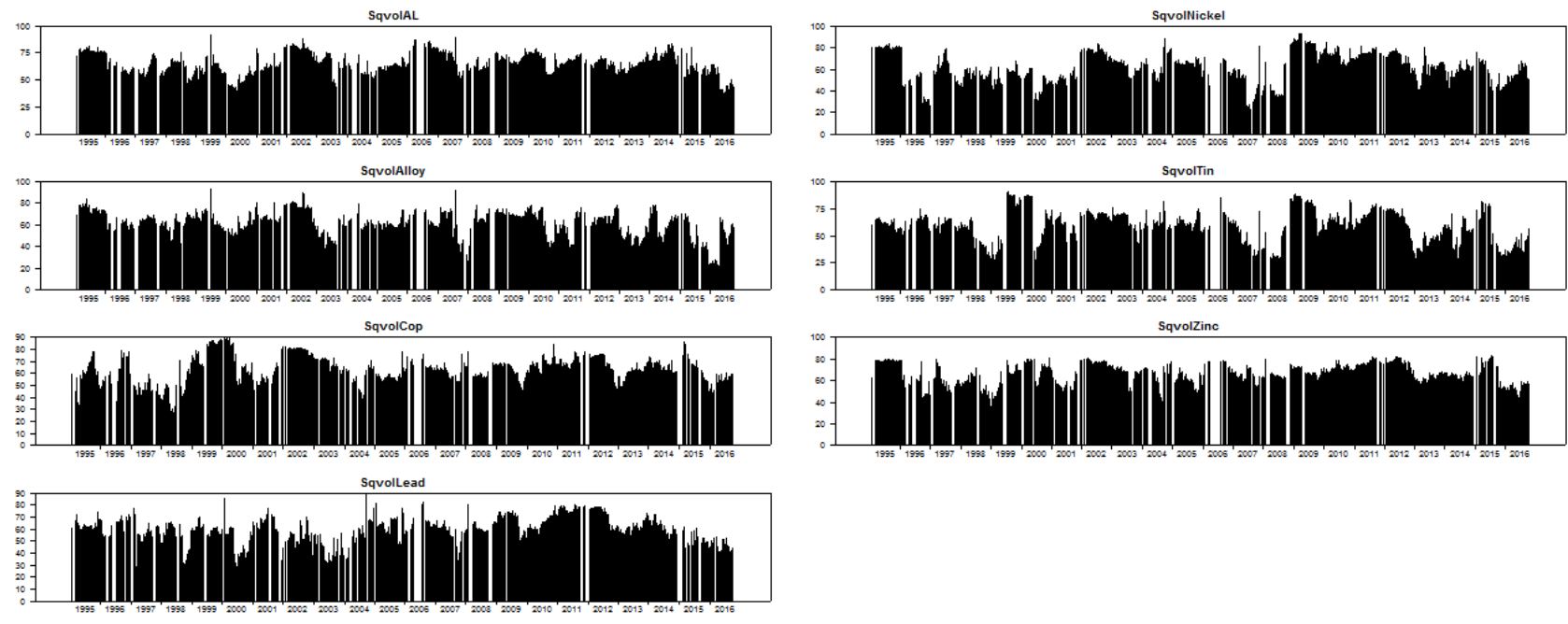

(a) Squared Volatility Spillovers Given
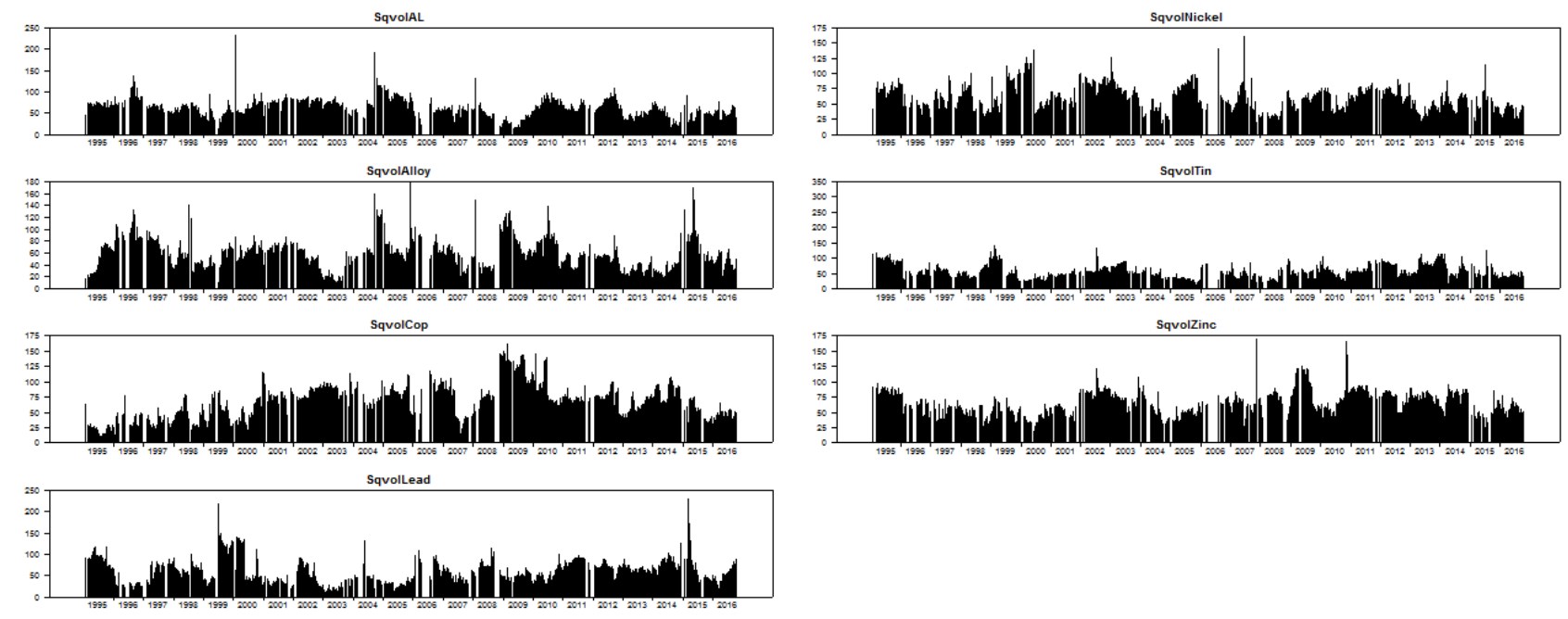

(b) Squared Volatility Spillovers Received 


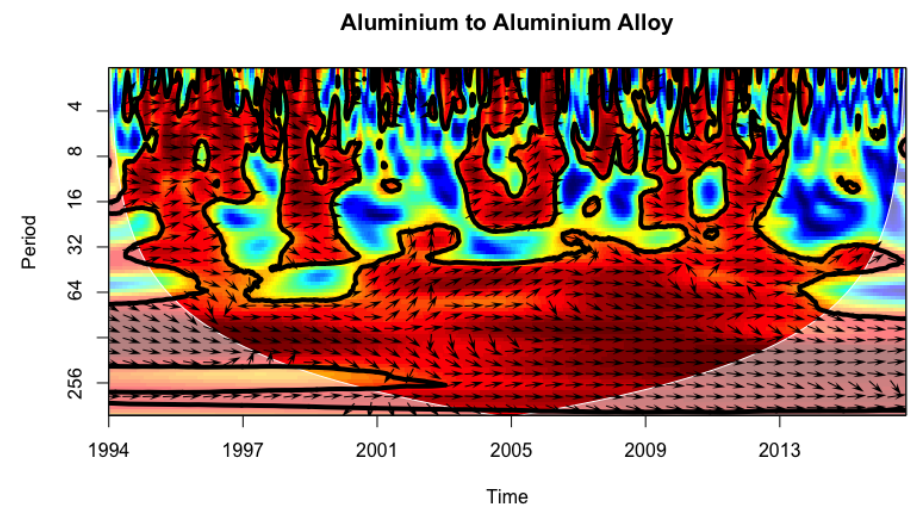

(a) fig 1

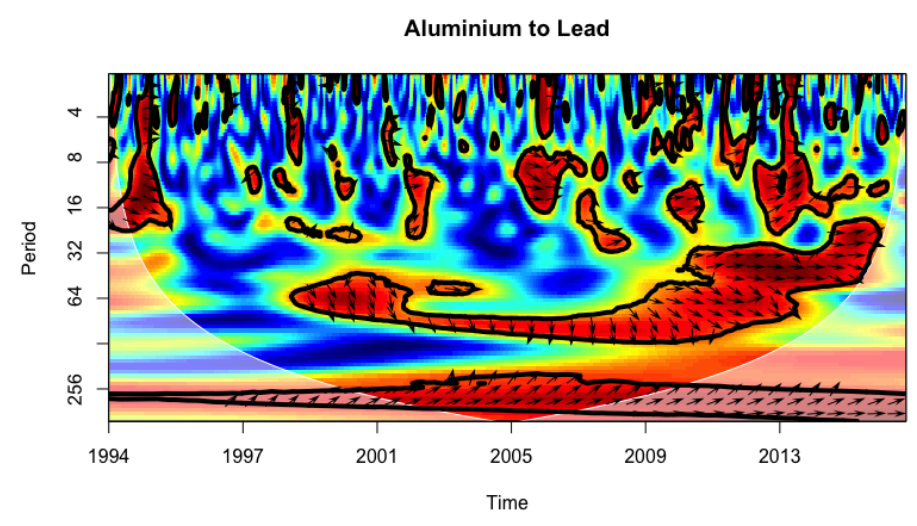

(c) fig 3

Aluminium to Tin

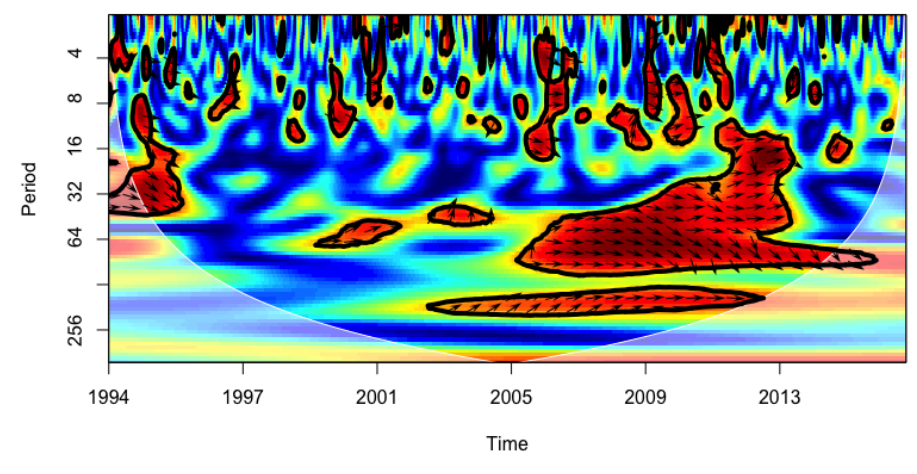

(e) fig 5

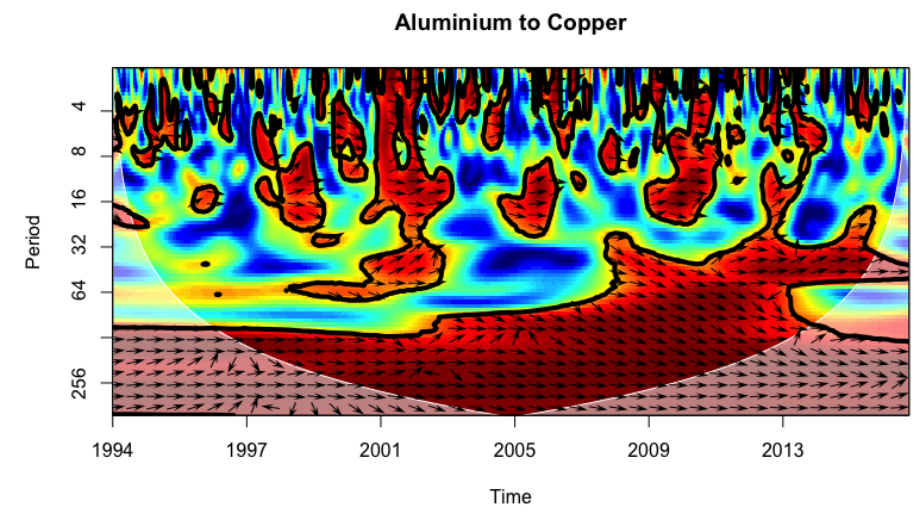

(b) fig 2

Aluminium to Nickel

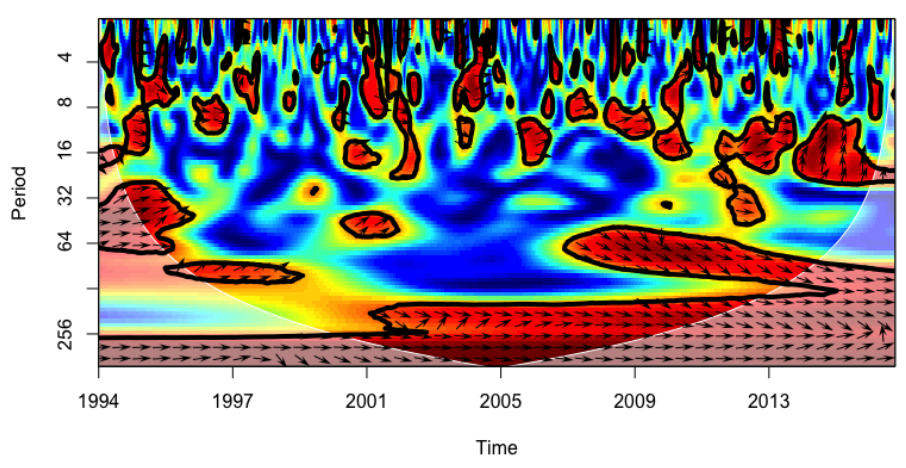

(d) fig 4

Aluminium to Zinc

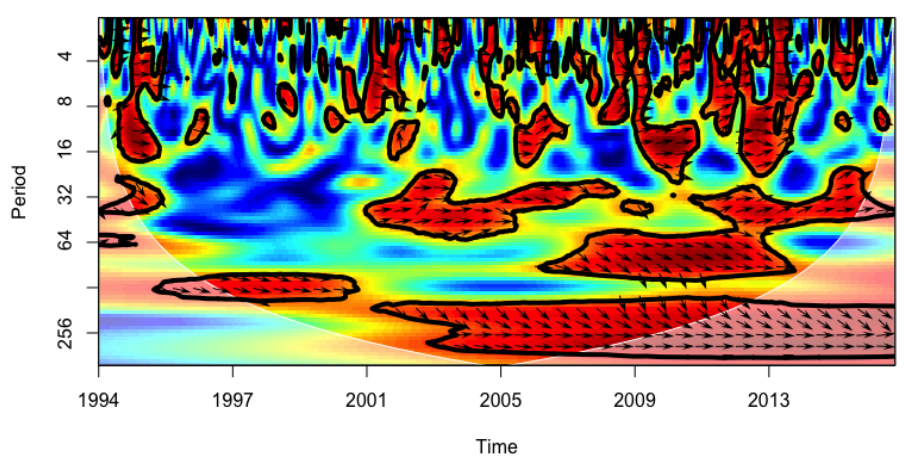

(f) fig 6 
Figure 7: Aluminium Alum. alloy Wavelet Coherence Plots

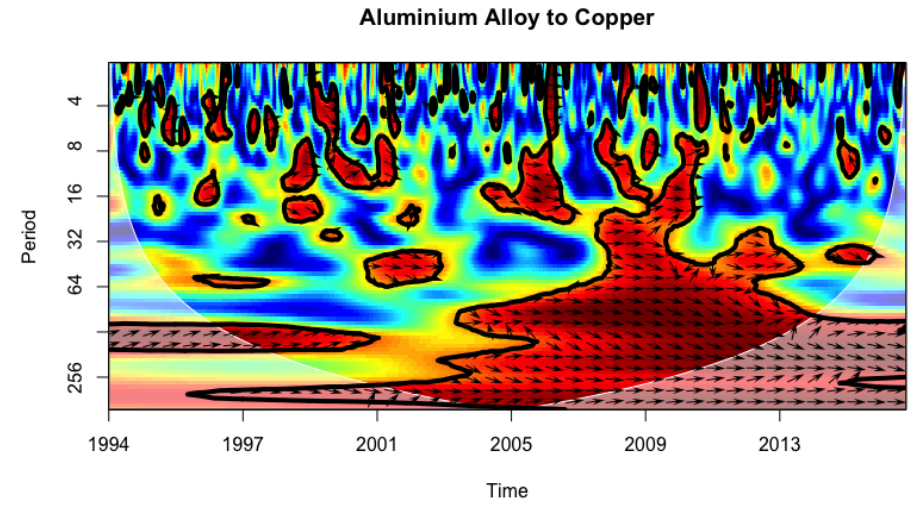

(a) fig 1

Aluminium Alloy to Nicke

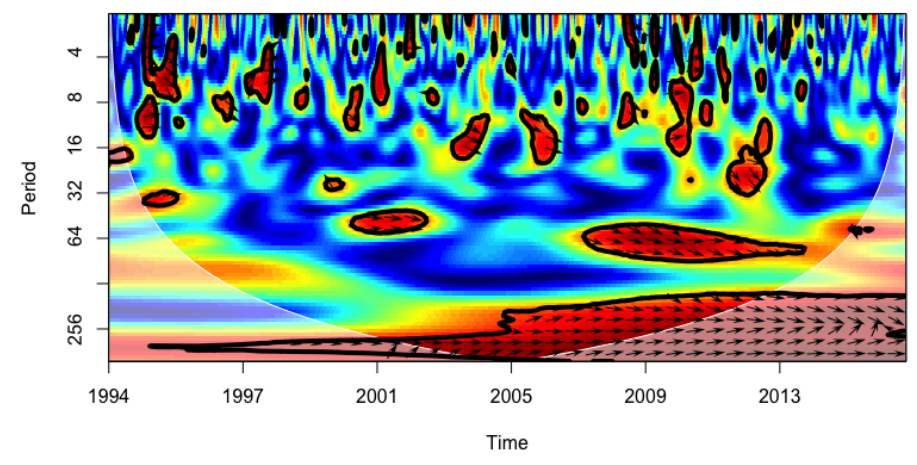

(c) fig 3

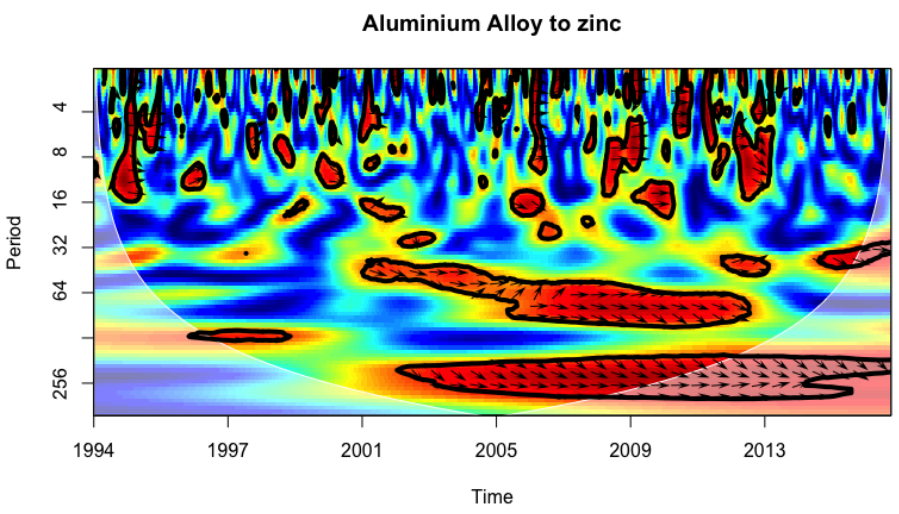

(e) fig 5

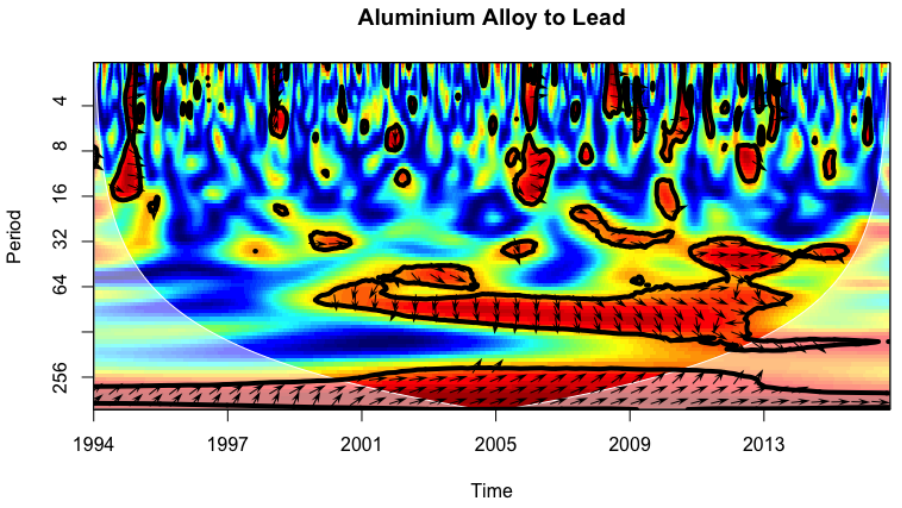

(b) fig 2

Aluminium Alloy to Tin

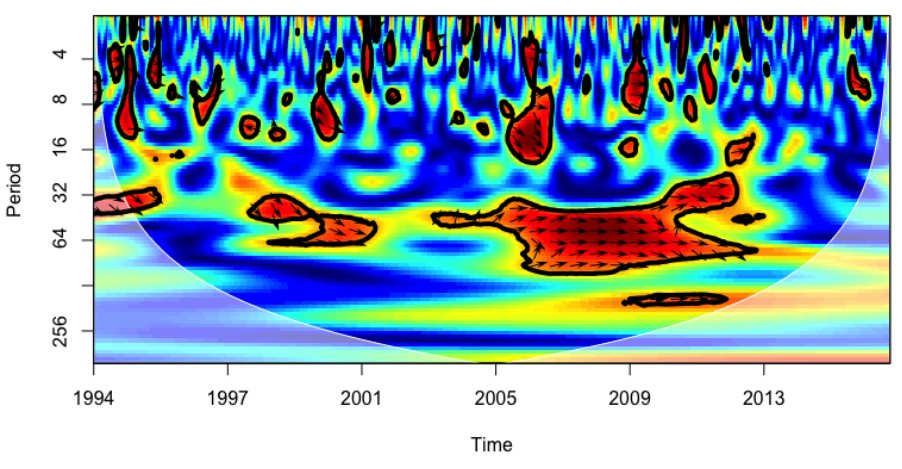

(d) fig 4 
Figure 8: Copper Wavelet Coherence Plots

Copper to Nicke

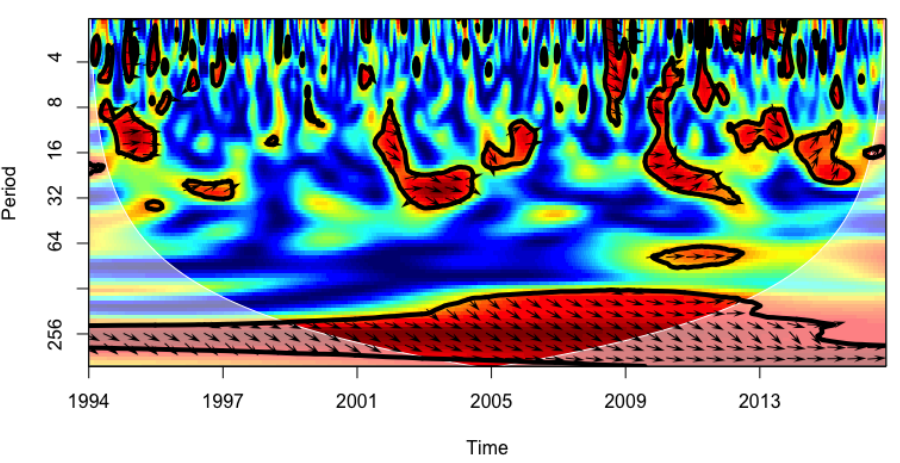

(a) fig 1

Copper to Zinc

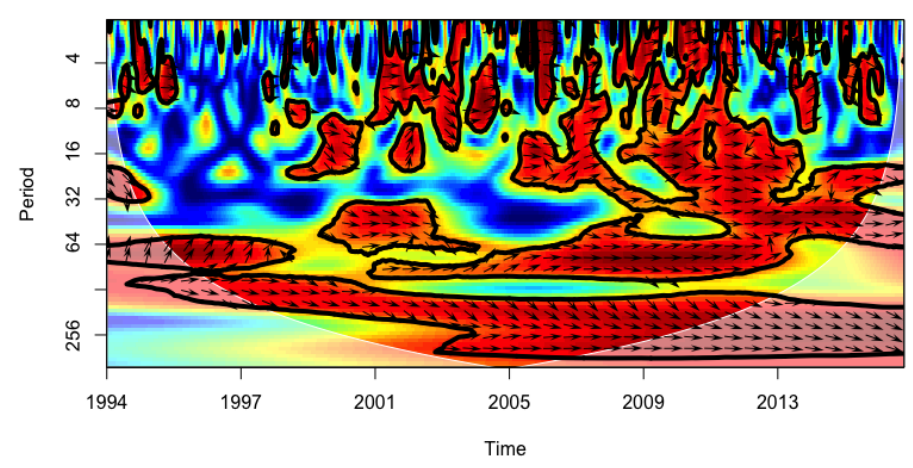

(c) fig 3

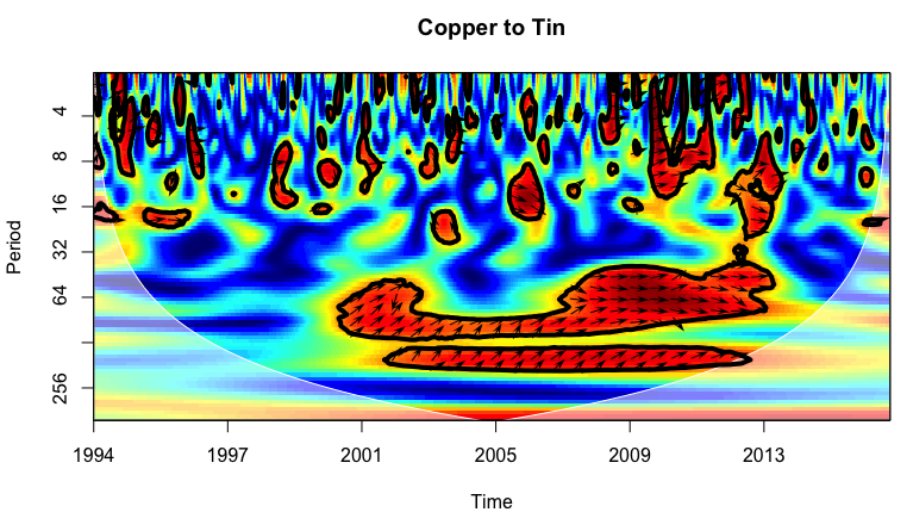

(b) fig 2

Copper to Lead

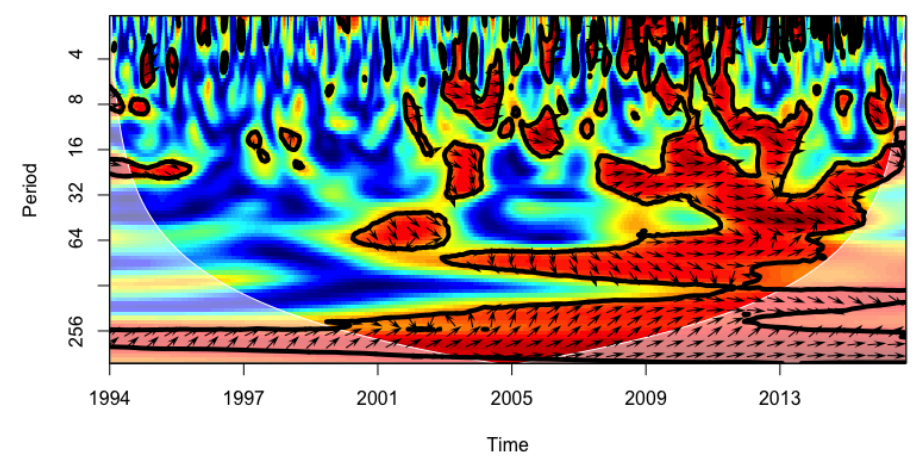

(d) fig 4 
Figure 9: Lead Wavelet Coherence Plots

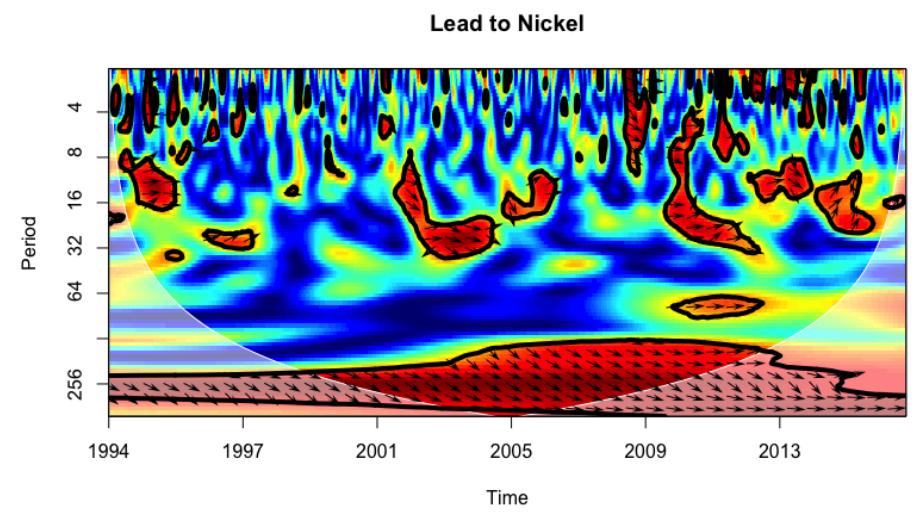

(a) fig 1

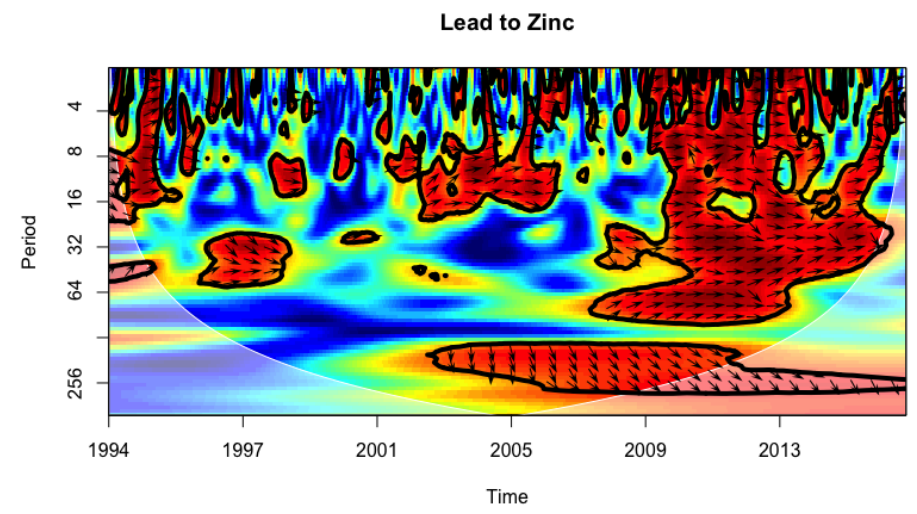

(c) fig 3

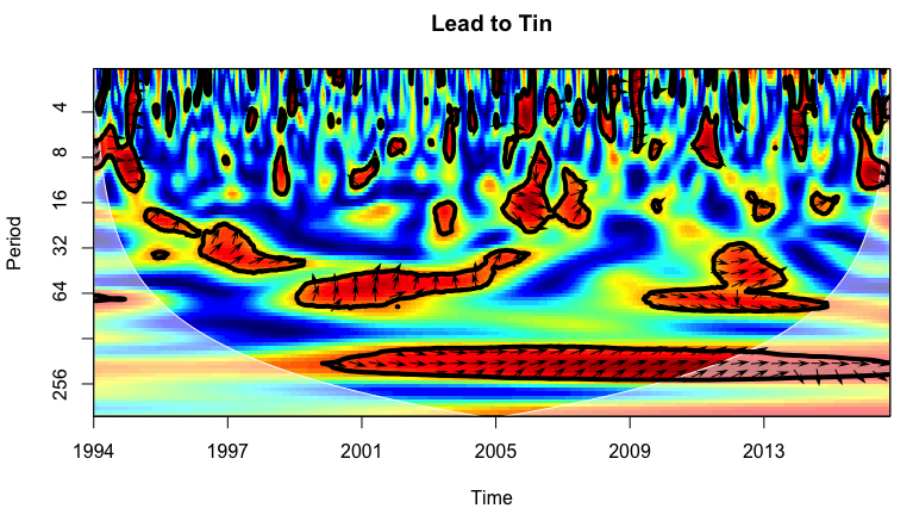

(b) fig 2 
Figure 10: Nickel and Zinc Wavelet Coherence Plots

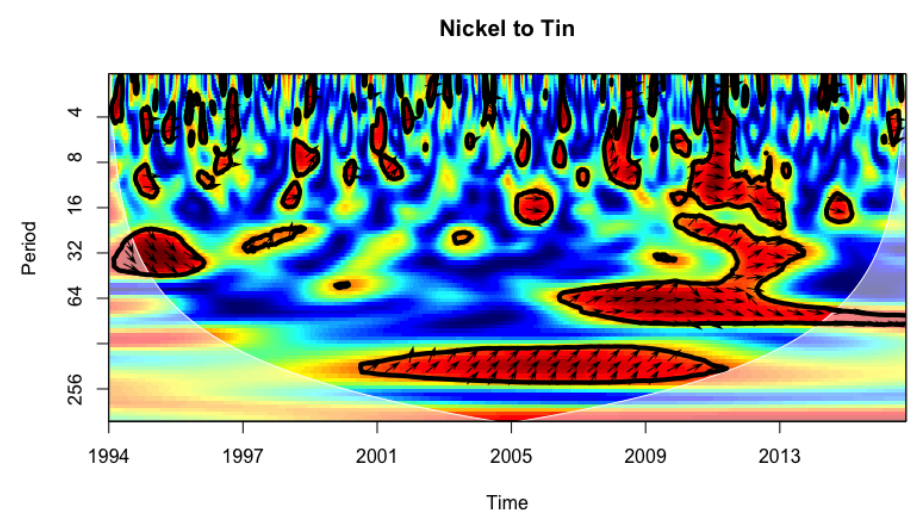

(a) fig 1

Tin to Zinc

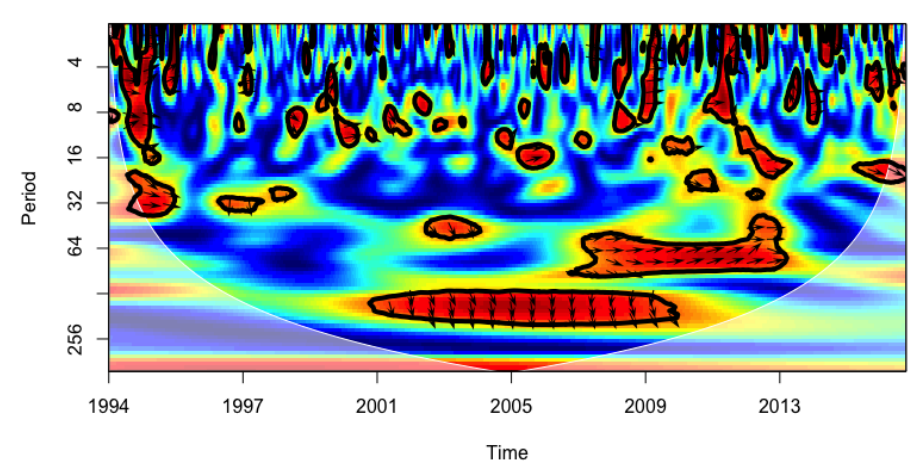

(c) fig 3

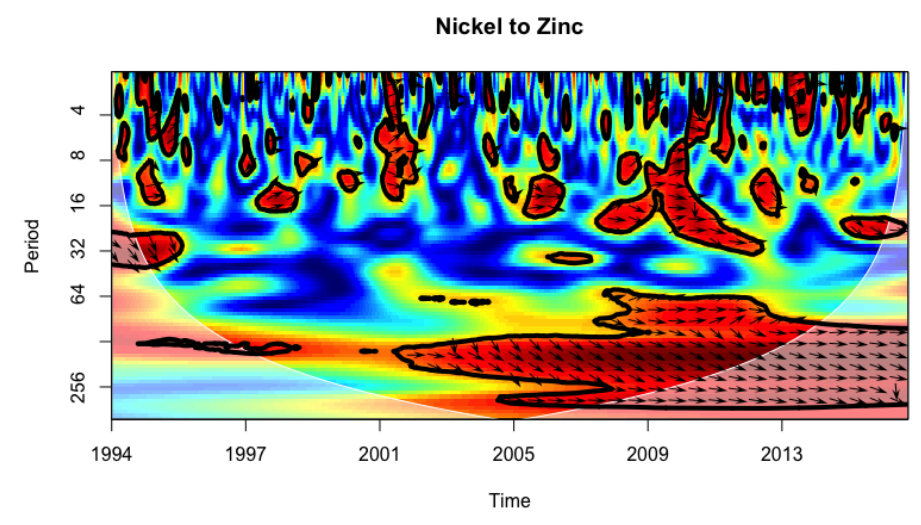

(b) fig 2 
Table 1: Descriptive Data

\begin{tabular}{|c|c|c|c|c|c|c|c|}
\hline & Aluminium & Alum. alloy & Copper & Lead & Nickel & Tin & Zinc \\
\hline \multicolumn{8}{|l|}{ Returns } \\
\hline Mean & 0.000 & 0.000 & 0.001 & 0.001 & 0.001 & 0.001 & 0.001 \\
\hline Median & 0.000 & 0.000 & 0.001 & 0.001 & 0.002 & 0.001 & 0.001 \\
\hline Maximum & 0.145 & 0.130 & 0.139 & 0.232 & 0.316 & 0.280 & 0.161 \\
\hline Minimum & -0.127 & -0.124 & -0.182 & -0.206 & -0.200 & -0.191 & -0.194 \\
\hline Std. Dev. & 0.028 & 0.024 & 0.035 & 0.043 & 0.048 & 0.035 & 0.037 \\
\hline Skewness & 0.088 & 0.007 & -0.222 & -0.150 & 0.171 & -0.162 & -0.394 \\
\hline Kurtosis & 4.808 & 6.600 & 5.611 & 5.953 & 6.626 & 9.273 & 6.250 \\
\hline Observations & 1189 & 1189 & 1189 & 1189 & 1189 & 1189 & 1189 \\
\hline \multicolumn{8}{|l|}{ Volatility } \\
\hline Mean & 1.018 & 0.892 & 1.100 & 1.219 & 1.302 & 1.055 & 1.138 \\
\hline Median & 0.976 & 0.850 & 1.044 & 1.155 & 1.255 & 1.007 & 1.080 \\
\hline Maximum & 2.294 & 2.171 & 2.737 & 2.911 & 3.733 & 3.190 & 2.787 \\
\hline Minimum & 0.370 & 0.109 & 0.409 & 0.436 & 0.379 & 0.000 & 0.439 \\
\hline Std. Dev. & 0.284 & 0.306 & 0.338 & 0.390 & 0.393 & 0.384 & 0.363 \\
\hline Skewness & 0.726 & 0.801 & 0.997 & 0.840 & 1.041 & 0.878 & 0.872 \\
\hline Kurtosis & 3.847 & 4.149 & 4.552 & 3.957 & 5.448 & 4.504 & 4.105 \\
\hline Observations & 1189 & 1189 & 1189 & 1189 & 1189 & 1189 & 1189 \\
\hline \multicolumn{8}{|c|}{ Squared Volatility } \\
\hline Mean & 0.001 & 0.001 & 0.001 & 0.002 & 0.002 & 0.001 & 0.001 \\
\hline Median & 0.000 & 0.000 & 0.000 & 0.001 & 0.001 & 0.000 & 0.000 \\
\hline Maximum & 0.021 & 0.017 & 0.033 & 0.054 & 0.100 & 0.078 & 0.038 \\
\hline Minimum & 0.000 & 0.000 & 0.000 & 0.000 & 0.000 & 0.000 & 0.000 \\
\hline Std. Dev. & 0.002 & 0.001 & 0.003 & 0.004 & 0.006 & 0.004 & 0.003 \\
\hline Skewness & 5.836 & 6.380 & 5.429 & 5.837 & 8.132 & 11.808 & 6.322 \\
\hline Kurtosis & 54.741 & 58.457 & 44.248 & 51.148 & 107.013 & 217.376 & 56.799 \\
\hline Observations & 1189 & 1189 & 1189 & 1189 & 1189 & 1189 & 1189 \\
\hline
\end{tabular}


Table 2: Return Spillovers

\begin{tabular}{|c|c|c|c|c|c|c|c|c|c|c|}
\hline From/To & Aluminium & Alum. alloy & Copper & Lead & Nickel & Tin & Zinc & From Others & Net & Conclusion \\
\hline Aluminium & 34.04 & 17.35 & 13.67 & 7.63 & 8.44 & 6.24 & 12.63 & 65.96 & 11.07 & Net-contributor \\
\hline Alum. alloy & 21.24 & 41.67 & 11.32 & 5.42 & 5.74 & 4.85 & 9.77 & 58.33 & -7.17 & Net-recipient \\
\hline Copper & 14.01 & 9.27 & 35.00 & 9.86 & 10.31 & 7.44 & 14.12 & 65.00 & 9.11 & Net-contributor \\
\hline Lead & 9.27 & 5.23 & 11.55 & 41.38 & 7.34 & 8.22 & 17.02 & 58.62 & -4.35 & Net-recipient \\
\hline Nickel & 10.90 & 5.87 & 13.23 & 7.92 & 43.15 & 8.49 & 10.44 & 56.85 & -7.21 & Net-recipient \\
\hline Tin & 8.67 & 5.43 & 10.03 & 9.19 & 9.41 & 47.49 & 9.79 & 52.51 & -10.04 & Net-recipient \\
\hline Zinc & 12.94 & 8.01 & 14.32 & 14.25 & 8.41 & 7.24 & 34.82 & 65.18 & 8.58 & Net-contributor \\
\hline Contrib. to others & 77.04 & 51.16 & 74.12 & 54.27 & 49.64 & 42.48 & 73.76 & 422.45 & & \\
\hline Contrib. inc own & 111.08 & 92.83 & 109.11 & 95.65 & 92.79 & 89.96 & 108.58 & $60 \%$ & & \\
\hline
\end{tabular}

Table 3: Volatility Spillovers

\begin{tabular}{lrrrrrrrrrr}
\hline From/To & Aluminium & Alum. alloy & Copper & Lead & Nickel & Tin & Zinc & From Others & Net & Conclusion \\
\hline Aluminium & 49.59 & 16.23 & 9.71 & 4.66 & 4.49 & 3.80 & 11.51 & 50.41 & 1.85 & Net-contributor \\
Alum. alloy & 19.28 & 63.40 & 5.87 & 2.87 & 2.20 & 1.69 & 4.69 & 36.60 & -2.66 & Net-recipient \\
Copper & 8.31 & 5.46 & 56.16 & 9.17 & 6.07 & 4.36 & 10.47 & 43.84 & 6.54 & Net-contributor \\
Lead & 5.27 & 3.02 & 8.26 & 56.77 & 5.11 & 7.09 & 14.48 & 43.23 & 2.45 & Net-contributor \\
Nickel & 4.94 & 2.73 & 9.94 & 7.23 & 59.42 & 4.87 & 10.87 & 40.58 & -10.96 & Net-recipient \\
Tin & 5.30 & 2.30 & 6.67 & 9.05 & 5.76 & 62.15 & 8.77 & 37.85 & -9.86 & Net-recipient \\
Zinc & 9.15 & 4.20 & 9.93 & 12.70 & 6.00 & 6.17 & 51.85 & 48.15 & 12.64 & Net-contributor \\
Contrib. to others & 52.26 & 33.95 & 50.38 & 45.68 & 29.62 & 27.99 & 60.79 & 300.66 & & \\
Contrib. inc own & 101.85 & 97.34 & 106.54 & 102.45 & 89.04 & 90.14 & 112.64 & & $43.0 \%$ \\
\hline
\end{tabular}


Table 4: Squared Volatility Spillovers

\begin{tabular}{lrrrrrrrrrr}
\hline From/To & Aluminium & Alum. alloy & Copper & Lead & Nickel & Tin & Zinc & From Others & Net & Conclusion \\
\hline Aluminium & 48.46 & 20.13 & 9.19 & 3.96 & 6.75 & 1.82 & 9.69 & 51.54 & -2.41 & Net-recipient \\
Alum. alloy & 19.93 & 55.52 & 9.80 & 3.25 & 3.01 & 1.06 & 7.43 & 44.48 & 18.97 & Net-contributor \\
Copper & 6.07 & 10.53 & 53.07 & 6.61 & 7.38 & 3.80 & 12.55 & 46.93 & 20.57 & Net-contributor \\
Lead & 4.50 & 8.11 & 11.08 & 49.86 & 6.51 & 7.93 & 12.00 & 50.14 & -6.53 & Net-recipient \\
Nickel & 6.83 & 8.34 & 12.99 & 6.99 & 48.27 & 8.25 & 8.33 & 51.73 & -13.23 & Net-recipient \\
Tin & 2.12 & 8.33 & 11.36 & 11.87 & 8.81 & 51.68 & 5.83 & 48.32 & -22.44 & Net-recipient \\
Zinc & 9.69 & 8.00 & 13.07 & 10.93 & 6.04 & 3.02 & 49.24 & 50.76 & 5.07 & Net-contributor \\
Contrib. to others & 49.13 & 63.45 & 67.49 & 43.61 & 38.50 & 25.87 & 55.83 & 343.89 & & \\
Contrib. inc own & 97.59 & 118.97 & 120.57 & 93.47 & 86.77 & 77.56 & 105.08 & $49.1 \%$ & & \\
\hline
\end{tabular}


Table 5: NARLD Causality Results

\begin{tabular}{|c|c|c|c|c|c|c|c|}
\hline Direction & Caused by & Direction & Caused by & Direction & Caused by & Direction & Caused by \\
\hline $\begin{array}{l}\text { Alum. alloy - } \\
\text { Alum. alloy - } \\
\text { Alum. alloy - } \\
\text { Alum. alloy - } \\
\text { Alum. alloy + } \\
\text { Alum. alloy + } \\
\text { Alum. alloy + } \\
\text { Alum. alloy + } \\
\text { Aluminum - } \\
\text { Aluminum - } \\
\text { Aluminum - } \\
\text { Aluminum - } \\
\text { Aluminum - } \\
\text { Aluminum - } \\
\text { Aluminum + } \\
\text { Aluminum + } \\
\text { Aluminum + } \\
\text { Aluminum + }\end{array}$ & $\begin{array}{l}\text { Aluminum + } \\
\text { Aluminum - } \\
\text { Zinc }+ \\
\text { Lead }+ \\
\text { Tin }+ \\
\text { Aluminum + } \\
\text { Zinc + } \\
\text { Copper - } \\
\text { Aluminum + } \\
\text { Alum. alloy - } \\
\text { Copper - } \\
\text { Alum. alloy + } \\
\text { Copper + } \\
\text { Tin - } \\
\text { Zinc + } \\
\text { Alum. alloy - } \\
\text { Aluminum - } \\
\text { allov }+\end{array}$ & $\begin{array}{l}\text { Copper - } \\
\text { Copper - } \\
\text { Copper - } \\
\text { Copper + } \\
\text { Copper + } \\
\text { Copper + } \\
\text { Copper + } \\
\text { Copper + } \\
\text { Copper + } \\
\text { Lead - } \\
\text { Lead - } \\
\text { Lead - } \\
\text { Lead - } \\
\text { Lead - } \\
\text { Lead + } \\
\text { Lead + }\end{array}$ & $\begin{array}{l}\text { Alum. alloy - } \\
\text { Aluminum - } \\
\text { Aluminum + } \\
\text { Aluminum + } \\
\text { Copper - } \\
\text { Alum. alloy + } \\
\text { Zinc + } \\
\text { Nickel + } \\
\text { Zinc - } \\
\text { Aluminum - } \\
\text { Nickel - } \\
\text { Nickel + } \\
\text { Aluminum + } \\
\text { Alum. alloy + } \\
\text { Aluminum + } \\
\text { Copper - }\end{array}$ & $\begin{array}{l}\text { Tin - } \\
\text { Tin - } \\
\text { Tin - } \\
\text { Tin - } \\
\text { Tin - } \\
\text { Tin + } \\
\text { Tin + } \\
\text { Zinc - } \\
\text { Zinc - } \\
\text { Zinc - } \\
\text { Zinc - } \\
\text { Zinc - } \\
\text { Zinc - } \\
\text { Zinc - } \\
\text { Zinc + } \\
\text { Zinc + } \\
\text { Zinc + } \\
\text { Zinc + }\end{array}$ & $\begin{array}{l}\text { Aluminum + } \\
\text { Aluminum - } \\
\text { Nickel - } \\
\text { Copper - } \\
\text { Tin + } \\
\text { Lead - } \\
\text { Tin - } \\
\text { Zinc + } \\
\text { Nickel - } \\
\text { Alum. alloy - } \\
\text { Alum. alloy + } \\
\text { Copper + } \\
\text { Aluminum - } \\
\text { Copper - } \\
\text { Aluminum + } \\
\text { Tin - } \\
\text { Alum. alloy + } \\
\text { Nickel - }\end{array}$ & $\begin{array}{l}\text { Nickel - } \\
\text { Nickel - } \\
\text { Nickel - } \\
\text { Nickel - } \\
\text { Nickel - } \\
\text { Nickel - } \\
\text { Nickel + } \\
\text { Nickel + } \\
\text { Nickel + } \\
\text { Nickel + } \\
\text { Nickel + }\end{array}$ & $\begin{array}{l}\text { Alum. alloy + } \\
\text { Aluminum + } \\
\text { Alum. alloy - } \\
\text { Zinc - } \\
\text { Zinc + } \\
\text { Aluminum - } \\
\text { Zinc + } \\
\text { Aluminum + } \\
\text { Nickel - } \\
\text { Copper - } \\
\text { Alum. alloy + }\end{array}$ \\
\hline
\end{tabular}

